\title{
Paper-based Microfluidic Aptasensors
}

\author{
Tao Minga,b, Jinping Luo ${ }^{a, b}$, Juntao Liu ${ }^{a, b}$, Shuai Sun ${ }^{a, b}$, Yu Xing, ${ }^{a, b}$, Hao Wang ${ }^{\text {a,b }}$, Guihua \\ Xiao $^{\text {a,b }}{ }^{\text {, Yu Deng }}{ }^{c}$, Yan Cheng ${ }^{c}$, Zhugen Yang $^{d}$, Hongyan Jin ${ }^{c^{*}}$, Xinxia Caia ${ }^{a, b^{*}}$ \\ aAerospace Information Research Institute, Chinese Academy of Sciences, Beijing 100094, PR China. \\ ${ }^{\mathrm{b}}$ University of Chinese Academy of Sciences, Beijing 100049, PR China \\ c Obstetrics and Gynecology Department, Peking University First Hospital, Beijing 100034, PR China \\ ${ }^{\mathrm{d}}$ Cranfield Water Science Institute, Cranfield University, Cranfield MK43 0AL, United Kingdom \\ *Corresponding authors. Email addresses: maggijhy@163.com (H. Jin), xxcai@mail.ie.ac.cn (X. Cai)
}

\begin{abstract}
For in-situ disease markers detection, point-of-care (POC) diagnosis has great advantages in speed and cost compared with traditional techniques. The rapid diagnosis, prognosis, and surveillance of diseases can significantly reduce disease-related mortality and trauma. Therefore, increasing attention has been paid to the POC diagnosis devices due to their excellent diagnosis speed and portability. Over the past ten years, paperbased microfluidic aptasensors have emerged as a class of critical POC diagnosis devices and various aptasensors have been proposed to detect various disease markers. However, most aptasensors need further improvement before they can actually enter the market and be widely used. There is thus an urgent need to sort out the key points of preparing the aptasensors and the direction that needs to be invested in. This review summarizes the representative articles in the development of paper-based microfluidic aptasensors. These works can be divided into paper-based optical aptasensors and paper-based electrochemical aptasensors according to their output signals. Significant focus is applied to these works according to the following three parts: (1) The ingenious design of device structure; (2) Application and synthesis of nanomaterial; (3) The detection principle of the proposed aptasensor. This is a detailed and comprehensive review of paper-based microfluidic aptasensors. The accomplishments and shortcomings of the current aptasensors are outlined, the development direction and the future prospective are given. It is hoped that the research in this review can provide a reference for further development of more advanced, more effective paper-based microfluidic aptasensors for POC disease markers diagnosis.
\end{abstract}

Keywords: Aptasensor; Paper-based device; Microfluidic chip; Portable equipment; Nanomaterial; Point-ofcare Diagnosis;

\section{Introduction}

Cancer has become the biggest threat to human life (Xiao et al., 2017). Approximately 8.8 million people die of cancer each year worldwide. In addition, various pathogens, hormone imbalances, etc., can lead to human disease (Bezinge et al., 2020). Therefore, rapid, accurate diagnostic devices are in great demand for the diagnosis, prognosis, and surveillance of diseases via detection of specific disease markers (Gutiérrez-capitán et al., 2020). The most applicable device formats allow diagnosis near patients, in places with limited resources, and in rural areas (Vashist and Luong, 2016). Some sensitive, reliable technology, such as enzyme-linked immunosorbent assays, cannot be used widely in developing countries because of the limited availability of laboratory infrastructure, skilled personnel, and financial support (Hay Burgess et al., 2006). In contrast, POC diagnostics are rapid, simple, and inexpensive, and thus attract extensive attention for disease detection, especially in developing world that lack infrastructure and trained personnel (Carvalho et al., 2018; Harpaz et al., 2017; Citartan and Tang, 2019). Moreover, due to their outstanding characteristics, POC diagnostics are 
very suitable for the prevention and control of infectious diseases (Yetisen et al., 2013).

Paper-based microfluidic aptasensors, combined with paper substrates, microfluidic channels and aptamers (Mahadeva et al., 2015), offer great potential for POC diagnosis, especially in resource-limited areas. Many diseases that can be cured in developed countries may have a high fatality rate in developing regions due to the lack of effective monitoring equipment and medical staff. Therefore, while many researchers continue to invest in making more sensitive aptasensors with a wider detection range, there is a trend for developing highly simplified, cost-effective paper-based aptasensors which can be interfaced with a portable device to get rid of the limitations of large medical equipment and professional medical staff.

Other approaches, such as lateral-flow devices, which use a membrane or paper strip to indicate the presence of biomarkers to achieve POC diagnosis. Although it can be performed simply, it is unable to mimic the multi-step procedures of laboratory-based assays that are essential to producing highly reproducible, quantitative, sensitive results. Unlike lateral-flow devices, paper-based microfluidic aptasensors offers the potential for more sophisticated capabilities than it. For example, a typical assay includes a platform, a fixed sample volume, a fixed assay time, a reader etc. The paper-based microfluidic aptasensors are able to integrating these components directly in the device, thus enabling POC diagnosis that require minimal effort and manipulation by the users. Users are only required to add samples to the device to get the results. That is to say, the key feature of paper-based microfluidic aptasensors is their ability to integrate various components, thus to link a patient to a result. Therefore, paper-based aptasensors have the potential to produce highly reproducible, quantitative, sensitive results to meet various demands (Chin et al., 2012).

Cellulose paper is a biocompatible material with a porous fiber web (Economou et al., 2018). The large surface area and porous structure of paper provide a large number of attachment points for nanomaterials, thus enabling detection signal amplification and improving test sensitivity (Ratajczak and Stobiecka, 2020; Akyazi et al., 2018; Mahato et al., 2017; Noviana et al., 2020). Since its discovery in 1990 (Ellington and Szostak, 1990), aptamer has attracted extensive attention for sensing applications and has been adopted as extensively as a probe in biosensing, therapeutic (Alshaer et al., 2018) (Carlson-Stevermer et al., 2017), specific-target capture assay(Citartan et al., 2016), decontamination (Bilibana et al., 2017), etc. This is because aptamers can probe for various objects, including metal ions (Wrzesinski and Jóźwiakowski, 2008), proteins (Eissa and Zourob, 2017), small molecules (Alsager et al., 2015)(Ruscito and DeRosa, 2016), cells, and biologically organisms (Ellington and Szostak, 1992) with high sensitivity. The process of selecting and synthesizing aptamers is controllable and aptamers are stable and can be modified by attaching various functional groups to their ends. Therefore, aptamers are very suitable probes for POC diagnostic devices.

In this review, we first introduce paper-based microfluidic devices, aptamer and nanomaterials, and then comprehensively discuss the representative aptasensors. These aptasensors are classified according to the various signals that they read, including optical and electrochemical signals. Optical aptasensors can be further categorized according to their sensing methods, which include colorimetry, fluorescence, and chemiluminescence (Mao et al., 2020a), Electrochemical aptasensors can also be categorized. Significant attention is given to the structure of the paper-based chip, the applied nanomaterials (Farzin and Shamsipur, 2018), and the detection principle. Finally, we summarize the review and provide insight into future prospects and development direction.

\section{Paper-based microfluidic aptasensors}

\subsection{Paper-based microfluidic devices}

Microfluidic devices have been greatly developed ( $\mathrm{Z}$. Li et al., 2017) since the first application of microfluidic technologies to analysis (Manz et al., 1992). In 2007, Whitesides and co-workers performed 
pioneering work on paper microfluidics (Martinez et al., 2007). The most remarkable feature of microfluidic devices is that their liquid flows are controllable. Thus, sample consumption, reagent use, and analysis time are minimized (Cao et al., 2017). Microfluidic devices are currently well-established for development of new life science methods and products (Yakoh et al., 2019).

Paper-based device dates back to the 1940s when it was used for chromatography (Martin and Synge, 1941). Nowadays, they have attracted more and more attention for being microfluidic devices substrates since hydrophobic and hydrophilic regions can easily be formed on them to generate microfluidic channels. Moreover, paper is a biocompatible porous fiber web. Its mesh structure allows sample to be filtered and its absorbency enables reagent storage (Mao et al., 2020b). Because of these characteristics, it has excellent potential as a microfluidic device substrate (Y. Yang et al., 2017).

Paper-based microfluidic devices ( $\mu$ PADs), combine the advantages of paper and microfluidics and have been subjects of rapid development for biological analysis (Gong and Sinton, 2017). $\mu$ PADs can integrate the required components so that all inspection steps occur on one device. They can also transport liquids without external force. These two characteristics make $\mu$ PADs fully functional system. Furthermore, the ability to operate on site is a great advantage in situations with limited technical infrastructure and untrained users. These characteristics give $\mu$ PADs excellent potential for use in POC diagnosis (Wei et al., 2016).

\subsection{Aptamers and Nanomaterials}

Aptamers have attracted extensive attention as molecular recognition elements for various applications (Zhang et al., 2020). This is because of their extremely high binding affinities towards targets (Du and Dong, 2016). Also, they are more stable and disposable than other probes such as antibodies (Wu and Kwon, 2016)(Choi et al., 2016). Those properties give aptasensors the potential to be used anywhere near a patient. Moreover, their sensitivities can be improved further via many approaches, such as isothermal amplification (Zhao et al., 2015). Aptasensors enable rapid detection of biomarkers, making such detection inexpensive and convenient.

Because of their high surface-to-volume ratios, nanomaterials exhibit unique physical and chemical properties that are completely different from those of traditional materials (Mohammadpour and MajidzadehA, 2020). Therefore, they play important roles in aptasensors development (Quesada-González and Merkoçi, 2015; Putzbach et al., 2013; Huang et al., 2019). Modification of aptamers and electrodes with various nanomaterials can provide various hair properties that enables aptasensors performance optimization (Aldewachi et al., 2018). Aptamers can attach to nanomaterials by forming bond with them. For example, the widely used Au-S bond is formed between the modified sulfhydryl group at the end of aptamers and AuNPs in the nanomaterial. Meanwhile, the signal changes caused by the combination of aptamers and target materials can be transformed and amplified by nanomaterials. Because of their excellent properties, many new nanomaterials have been discovered and applied to aptasensors development.

\subsection{Paper-based microfluidic aptasensors}

The work of the researchers is embodied in the realization of various mechanical functions through the delicate design of the equipment structure, the careful synthesis of nano materials to achieve the best performance, and the selection of the most selective and specific aptamers. The resulting paper-based microfluidic aptasensors can provide high specificity, high sensitivity POC diagnosis (Reboud et al., 2019).

As personal health care requirements increase, the demand for portable biosensors with good specificity and high sensitivity will increase as well. Therefore, paper-based microfluidic aptasensor have excellent potential to meet patient needs and become preferred POC diagnosis equipment. It is noted that since the paper- 
based microfluidic aptasensor is mainly based on filter paper, it is difficult to achieve dynamic monitoring in vivo. In order to continuously monitor a pathogen, we must repeat the testing process.

\section{Two types of paper-based microfluidic aptasensors}

\subsection{Paper-based optical aptasensors}

Optical aptasensors can detect targets via the optical signal generated by interaction between the aptamer and target (Moghimi et al., 2015). There are many methods of optical signal detection, including colorimetry, fluorescence, surface enhanced Raman spectroscopy (SERS), luminescence, and chemiluminescence (CL) (Fu and Wang, 2018) that are widely used in signal collection because of their excellent sensitivities and easy application (Feng et al., 2014)(Golub et al., 2009) (Liu et al., 2010) (Wang et al., 2010)(Devi et al., 2019). This section discusses proposed paper-based optical aptasensors (Table1).

\subsubsection{Colorimetric paper-based aptasensors}

The colorimetric method is an excellent detection method that is widely used in aptasensors preparation due to its simple detection principle, low equipment requirements, and intuitive results.

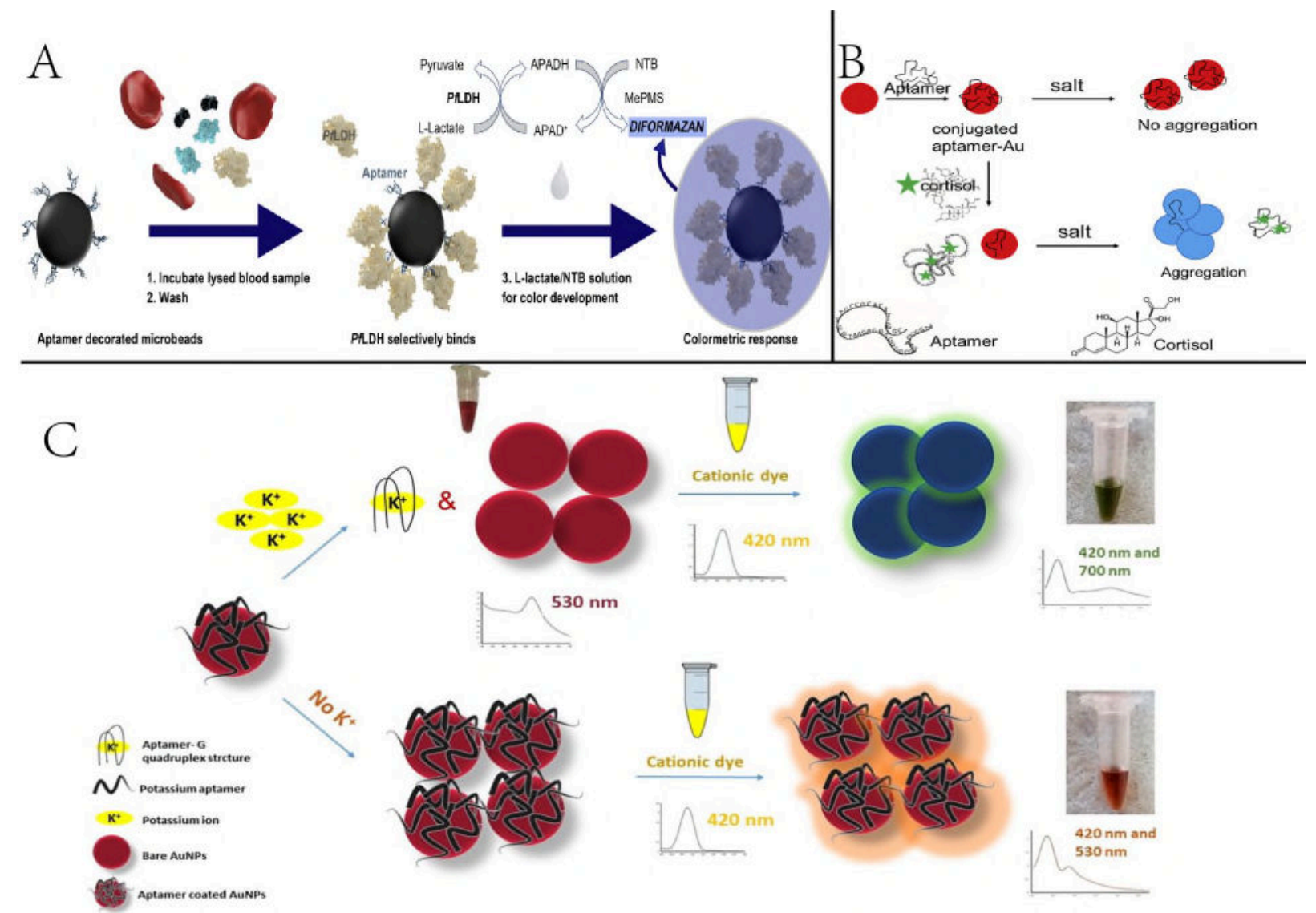

Fig. 1. Principles of representative colorimetric aptasensors. (A) Biomarker enzymatic activit is used for colorimetric detection. Reprinted with permission from Dirkzwager et al., 2016. Copyright (2016) American Chemical Society. (B) Colorimetric detection of cortisol using AuNPs (Dalirirad and Steckl, 2019); (C) a potassium detection diagram (Naderi et al., 2018).

Dirkzwager and co-workers did an excellent job in developing paper-based colorimetric aptasensor (Dirkzwager et al., 2016). In this work, the malaria biomarker Plasmodium falciparum lactate dehydrogenase is captured by its corresponding aptamer, which is immobilized on microbeads. Its intrinsic enzymatic activity can generate a visualizable blue color in response to Plasmodium-positive samples upon adding a development 
reagent. The detailed principle is shown in Fig.1 (A). This device achieves a detection limit of $5 \mathrm{ng} \mathrm{mL}^{-1}$.

AuNPs are the most commonly used nanomaterial in colorimetric aptasensors preparation (McConnell et al., 2020). The core principle is that AuNPs are in a free state when they are combined with the aptamers. After the aptamers combining with the targets, the AuNPs dissociate from the aptamer and aggregate, resulting in a color change. Based on this principle, an aptamer-based lateral flow strip assay was developed to detect cortisol in sweat in the field (Dalirirad and Steckl, 2019). The basic concept is shown in Fig.1(B). This aptasensor enables detection in a linear range of 1-100 $\mathrm{ng} \mathrm{mL}^{-1}$ with a visual detection limit of $1 \mathrm{ng} \mathrm{mL}^{-1}$. This can easily cover the range of free cortisol in sweat. Also, Nileshi and co-workers proposed a aptasensor for epinephrine detection (Saraf et al., 2017). Another aptasensor utilized interactions between AuNPs and a cationic dye was reported by Mahboube and co-workers for potassium $\left(\mathrm{K}^{+}\right)$ion detection (Naderi et al., 2018). This paper-based aptasensor enables detection of $\mathrm{K}^{+}$ions in a range from $10 \mu \mathrm{M}$ to $40 \mathrm{mM}$ with a detection limit of $6.2 \mu \mathrm{M}$. The basic concept is shown in Fig.1(C). In addition, Fakhri and co-workers developed a paper-based aptasensor that could detect lead $\left(\mathrm{Pb}^{+}\right)$ions in water (Fakhri et al., 2018). Whatman No. 1 and nylon filter papers were used, and the detection limits were $1.2 \mathrm{~nm}$ and $0.7 \mathrm{~nm}$, respectively.

\subsubsection{Fluorescent paper-based aptasensors}

Fluorescent analytical strategies, offer wild response ranges, customizability and excellent sensitivity, and thus have great potential to become an ideal quantitative biomarker detection method. Nanoparticles that provide fluorescence signals have attracted increasing attention with regard to aptasensor developments. This is because traditional organic dyes have the disadvantages of narrow absorption ranges, wide emission ranges, photobleaching, etc. Functionalized nanoparticle, such as AuNPs, graphene oxide (Lan et al., 2020), are used widely as acceptor and donor fluorophores because they are free of these problems (Pooja et al., 2017)(Dolatabadi et al., 2011)(Jamali et al., 2014)(Vaishanav et al., 2017).

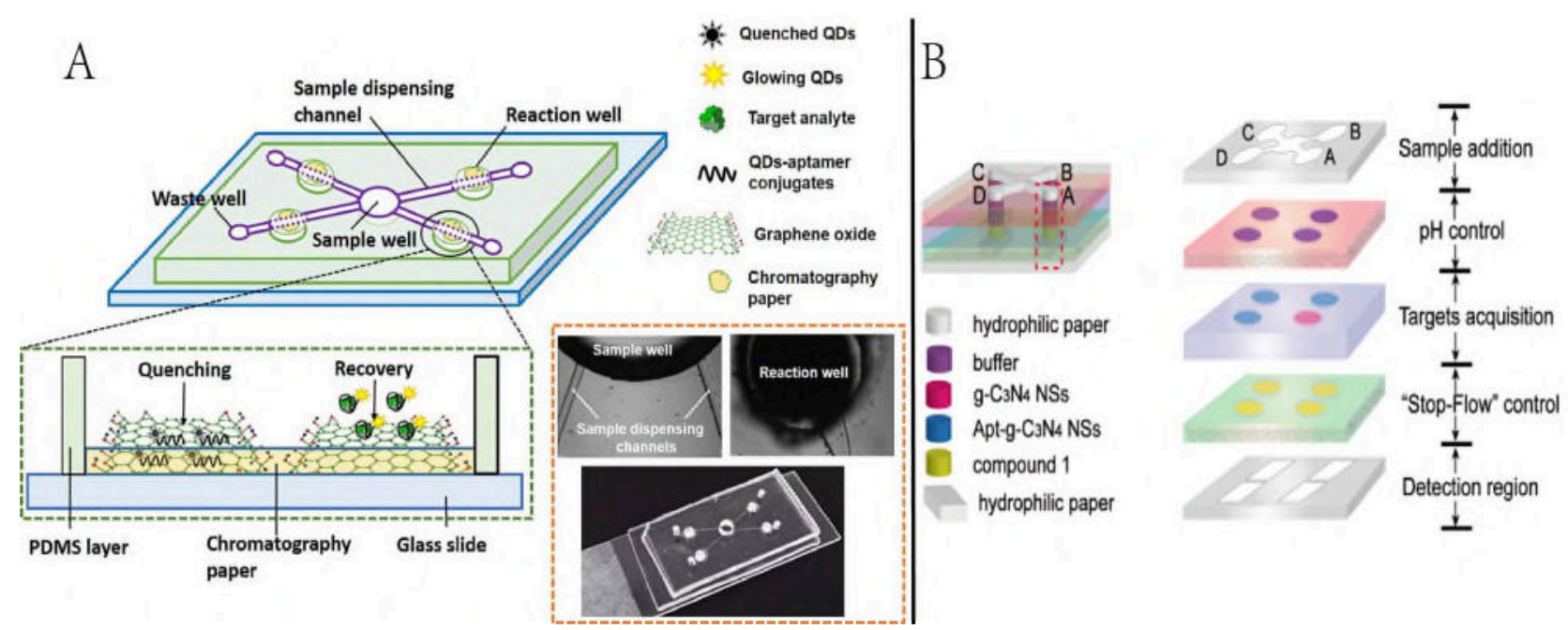

Fig. 2. Ingenious aptasensor structural designs. (A) Schematic and physical photograph of the aptasensor (Weng and Neethirajan, 2018); (B) an aptasensor simulation diagram. Reprinted with permission from L. Wang et al., 2019. Copyright (2019) American Chemical Society.

Graphene oxide (GO) and quantum dot (QD) are welcomed in developing fluorescent aptasensors. The basic principle of these device is that the aptamer-functionalized QDs' fluorescence is quenched after mixing with the GO, which will then recover with addition of targets. Based on the principle, Linlin Liang and coworkers developed a fluorescent aptasensor for multiplexed monitoring of three kinds of cancer cells (Liang et al., 2016). Another aptasensor was proposed to detect food allergens and food toxins (Weng and Neethirajan, 2018). As shown in Fig.2(A), this device can perform four independent tests simultaneously. 
Another study developed a ratio-metric fluorescent aptasensor for multiple aminoglycoside detection (L. Wang et al., 2019). The principle is as follows: aptamer/graphitic carbon nitride nanosheet-modified layers can catalyze o-phenylenediamine to fluorescent 2,3-diaminophenazine (DAP) in the presence of $\mathrm{H}_{2} \mathrm{O}_{2}$. Peroxidaselike activity is reduced when the aptamer is removed from the nanosheets via combination with targets, thus reducing DAP production. A schematic of the platform is shown in Fig.2(B). The platform consists of five paper layers via waterproof adhesive tape and four parallel channels. These provide reagent storage, jet path control, and signal processing, respectively.

A paper-based fluorescent aptasensor that relies on fluorescence resonance energy transfer (FRET) to detect a target protein was proposed (Geldert et al., 2017). The basic concept is shown in Fig.3(A). The performance of various types of papers were investigated to provide the best results. Only sensors made from printing paper can produce a specific, measurable fluorescence recovery. This device can provide a detection limit of $550 \mathrm{pM}$.

In addition, a paper-based aptasensor based on FRET and the super fluorescence quenching characteristics of GO sheets was proposed for 10-minute lead $\left(\mathrm{Pb}^{+}\right)$ion detection (Khoshbin et al., 2019). This system is based on the conformational transformations of aptamers from random coils to g-quadruple structures. $\mathrm{Pb} 2^{+}$ implanted on the platform could induce the surface to release specific aptamers, thus restoring fluorescence emission. The basic concept is shown in Fig.3(B). A linear relationship is noted in 5-70 pM and 0.07-20 nM ranges with a detection limit of $0.5 \mathrm{pM}$.

\subsubsection{Surface-enhanced Raman scattering paper-based aptasensors}

SERS is based on the principle of huge electromagnetic enhancement caused by the local surface plasmon resonance of a specific nanomaterial surface and offers high sensitivity (J.-F. Li et al., 2017)(Moskovits and Martin, 1985)(Sharma et al., 2012). Since its development in the 1980s (Fleischmann et al., 1974)(Jeanmaire and Van Duyne, 1977), it has been used broadly for detection of various inorganic and organic molecules, DNA chains, proteins,etc (Chen and Choo, 2008).

Shan-Wen $\mathrm{Hu}$ and co-workers developed a paper-based aptasensor (Hu et al., 2018). The principle is as follows: the corresponding aptamer is hybridized with complementary DNA labeled with CY-5 on its 3' terminus. After the aptamers combine with targets, the complementary DNA is replaced and washed away, resulting in a decrease of SERS signal. A schematic of the device is shown in Fig. 3(C).

\subsubsection{Chemiluminescence paper-based aptasensors}

$\mathrm{CL}$ analysis is based on the principle that the concentration of the test substance in the chemical detection system has a quantitative, linear relationship with the chemiluminescence intensity of the system under certain conditions. CL is widely used because of its high sensitivity, wide linear range and simple operation.

An excellent paper-based CL aptasensor was developed for $\mathrm{Hg}$ (II) detection (Liu et al., 2014). Phenyleneethynylene reagents on nanoporous silver (NPS@P-acid) are used as CL reagents. NPS @P-acid is combined with aptamer (S2) to form the NPS@P-acid conjugated aptamer probe (NPS@P-acid-S2). Another aptamer (S1) is immobilized on cellulosic paper that has been modified with N,N'-carbonyldiimidazole, which contains two acylimidazole leaving groups and is used in a simple, novel crosslinking strategy. Immobilization of S1 on paper occurs via the covalent combination of the aptamer amino group and hydroxy groups on the paper surface. When $\mathrm{Hg}$ (II) is captured by $\mathrm{S} 1$, the immobilized $\mathrm{Hg}$ (II) can capture NPS@P-acid-S2. CL is then induced via addition of permanganate. The $\mathrm{Hg}$ (II) concentration determines the CL strength. The device fabrication process is shown in Fig.3(D). This device enables detection in a range from $20 \mathrm{nM}$ to $0.5 \mu \mathrm{M}$ with a detection limit of $1 \mathrm{pM}$.

Another CL aptasensor was developed to detect hemin (X.-X. Zhang et al., 2019). Hemin was stacked on the microfluidic channel via field-amplified stacking and the CL reaction was initiated by loading a CL reagent (luminol- $\mathrm{H}_{2} \mathrm{O}_{2}$ ) onto the stacked band. A detection module was used to detect the detection results directly. 
The principle is as follows: upon introduction of luminol- $\mathrm{H}_{2} \mathrm{O}_{2}$, the excited state of the 3-aminophthalate dianion was produced in the presence of hemin, which acts as a catalyst under alkaline conditions. Photons were generated when the excited state of the 3-aminophthalate dianion returned to the ground state. A detection limit of $0.58 \mathrm{nM}$ and a linear range of 1-1000 $\mathrm{nM}$ were obtained.

\subsubsection{Electrochemiluminescence paper-based aptasensors}

Electrochemiluminescence (ECL) has also been used in the development of paper-based aptasensors because of its excellent characteristics, such as fast response speed, simple operation, and excellent sensitivity (L. Li et al., 2017). The ECL sensor has high repeatability and accuracy because it uses potential to start and adjust the output signal.

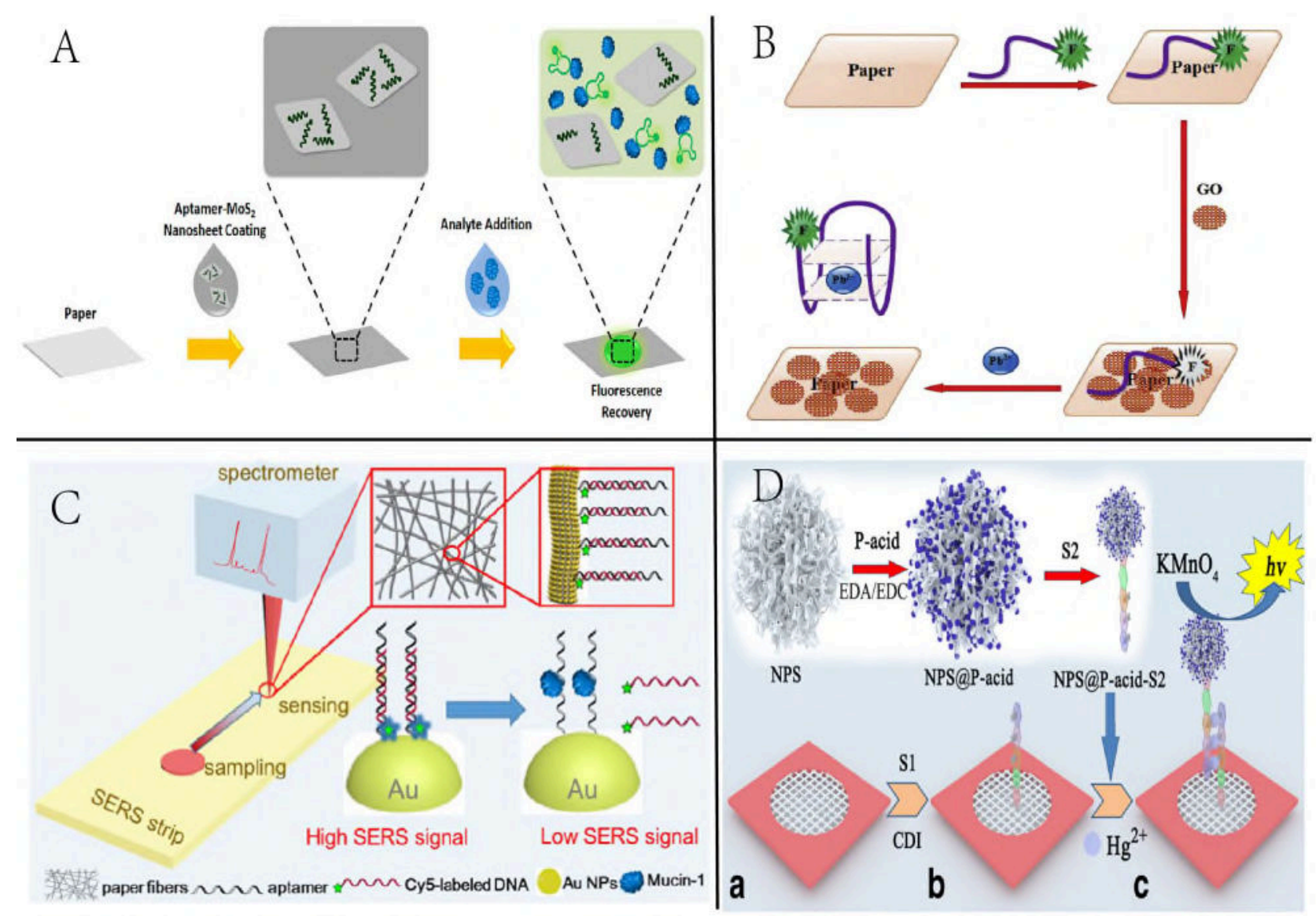

Fig. 3. Principles of representative paper-based optical aptasensors. (A) The sensing process of the aptasensor (Geldert et al., 2017); (B) The schematic diagram of the aptasensor (Khoshbin et al., 2019); (C) The principle and physical figure of the aptasensor (Hu et al., 2018); (D) The manufacturing process of the aptasensor (Liu et al., 2014).

A paper-based ECL aptasensor was developed to detect cancer cells (Wu et al., 2015). The device schematic is shown in Fig.4(A). The detection principle of this device is as follows: the electrode is modified with AuNPs to immobilize aptamers, which can capture the targets. The synthesized concanavalin A-labeled AuPd alloy nanoparticles (AuPd@Con-A) can bind onto the captured cells via specific recognition between Con-A and mannose on the cell surface, thus amplifying the ECL signal. This device could perform detection in the range of $450-1.0 \times 10^{7}$ cells $\mathrm{mL}^{-1}$ with a detection limit of 250 cells $\mathrm{mL}^{-1}$. 
Table.1: A list of the paper-based optical microfluidic aptasensors

\begin{tabular}{|c|c|c|c|c|}
\hline Signal & $\begin{array}{l}\text { Nanomaterial/biomateri } \\
\text { al }\end{array}$ & Linear Range & LOD & Reference \\
\hline Colormetric & Microbeads & $5-5000 \mathrm{ng} \mathrm{mL}^{-1}$ & $5000 \mathrm{pg} \mathrm{mL}^{-1}$ & $\begin{array}{l}\text { (Dirkzwager et } \\
\text { al., 2016) }\end{array}$ \\
\hline Colormetric & AuNPs & $1-100 \mathrm{ng} \mathrm{mL}^{-1}$ & $1000 \mathrm{pg} \mathrm{mL}^{-1}$ & $\begin{array}{l}\text { (Dalirirad and } \\
\text { Steckl, 2019) }\end{array}$ \\
\hline Colormetric & AuNPs & - & $0.9 \mathrm{nM}$ & $\begin{array}{l}\text { (Saraf et al., } \\
\text { 2017) }\end{array}$ \\
\hline Colormetric & AuNPs & $10-40 \mu \mathrm{M}$ & $6.2 \mu \mathrm{M}$ & $\begin{array}{l}\text { (Naderi et al., } \\
2018 \text { ) }\end{array}$ \\
\hline Colormetric & AuNPs & $10 \mathrm{nM}-1 \mathrm{mM}$ & $0.7 \mathrm{nM}$ & $\begin{array}{l}\text { (Fakhri et al., } \\
\text { 2018) }\end{array}$ \\
\hline Fluorescence & 2,3-diaminophenazine & $\begin{array}{l}0.01-30 \mathrm{ng} \mathrm{mL}^{-1} \\
0.1-150 \mathrm{ng} \mathrm{mL^{-1 }} \\
0.05-150 \mathrm{ng} \mathrm{mL}^{-1}\end{array}$ & $\begin{array}{l}0.023 \mathrm{ng} \mathrm{mL}^{-1} \\
0.069 \mathrm{ng} \mathrm{mL}^{-1} \\
0.045 \mathrm{ng} \mathrm{mL}^{-1}\end{array}$ & $\begin{array}{l}\text { (L. Wang et al., } \\
\text { 2019) }\end{array}$ \\
\hline Fluorescence & MoS2 nanosheets & - & $550 \mathrm{pM}$ & $\begin{array}{l}\text { (Geldert et al., } \\
\text { 2017) }\end{array}$ \\
\hline Fluorescence & Graphene oxide & $\begin{array}{l}\text { 5-70 pM and } \\
0.07-20 \mathrm{nM}\end{array}$ & $0.5 \mathrm{pM}$ & $\begin{array}{l}\text { (Khoshbin et al., } \\
\text { 2019) }\end{array}$ \\
\hline SERS-based & AuNPs & $0.005-50 \mu \mathrm{g} \mathrm{mL}^{-1}$ & $5 \mathrm{ng} \mathrm{mL}^{-1}$ & (Hu et al., 2018) \\
\hline Chemiluminescence & NPS@P-acid & $0.02-0.5 \mu \mathrm{M}$ & $1 \mathrm{pM}$ & (Liu et al., 2014) \\
\hline Chemiluminescence & - & $1-1000 \mathrm{nM}$ & $0.58 \mathrm{nM}$ & $\begin{array}{l}\text { (X.-X. Zhang et al., } \\
\text { 2019) }\end{array}$ \\
\hline $\begin{array}{l}\text { Electro } \\
\text { chemiluminescence }\end{array}$ & AuNPs/ AuPd & $\begin{array}{l}450-1.0 \times 10^{7} \text { cells } \\
\mathrm{mL}^{-1}\end{array}$ & 250 cells $\mathrm{mL}^{-1}$ & (Wu et al., 2015) \\
\hline $\begin{array}{l}\text { Electro } \\
\text { chemiluminescence }\end{array}$ & $\mathrm{AuPd} / \mathrm{PtNi}$ & $\begin{array}{l}480-2.0 \times 10^{7} \text { cells } \\
\mathrm{mL}^{-1}\end{array}$ & 300 cells $\mathrm{mL}^{-1}$ & (Wu et al., 2016) \\
\hline $\begin{array}{l}\text { Electro } \\
\text { chemiluminescence }\end{array}$ & AuNPs & $0.025-50 \mathrm{nM}$ & $8.33 \mathrm{pM}$ & (Ma et al., 2017) \\
\hline $\begin{array}{l}\text { Electro } \\
\text { chemiluminescence }\end{array}$ & $\begin{array}{l}\text { Patchy gold coated } \mathrm{Fe}_{3} \mathrm{O}_{4} \\
\text { hybrid nanoparticles }\end{array}$ & $\begin{array}{l}0.0001-15 \mathrm{ng} \\
\mathrm{mL}^{-1}\end{array}$ & $0.03 \mathrm{pg} \mathrm{mL}^{-1}$ & $\begin{array}{l}\text { (Zhang et al., } \\
\text { 2018) }\end{array}$ \\
\hline Luminescence & $\begin{array}{l}\text { Upconversion } \\
\text { nanoparticles }\end{array}$ & $0.5-80 \mathrm{ng} \mathrm{mL}^{-1}$ & - & (Jiang et al., 2017) \\
\hline
\end{tabular}

The team also reported another ECL aptasensor with a similar mechanism in 2016 (Wu et al., 2016). This

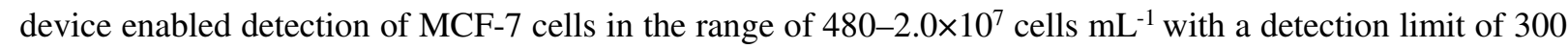
cells $\mathrm{mL}^{-1}$.

In addition, a origami ECL aptasensor was developed on a AuNP modified paper working electrode (AuPWE) (Yan et al., 2013). This device contains a split single aptamer: one fragment with a thiolated 5'end is immobilized onto Au-PWE via Au-S interaction, the second fragment with an amine 3'end is labeled with ECL 
labels, the Phenyleneethynylene derivative modified nanotubular mesoporous $\mathrm{Pt}-\mathrm{Ag}$ alloy nanoparticles (Pacid-Pt-Ag ANPs). And the corresponding target can trigger the partial hybridization of the two fragments, leading to the increase of ECL intensity. This work introduces the preparation of AuNP-modified paper electrode and its properties in detail.

Another ECL aptasensor was developed to detect peptides(Ma et al., 2017). Detailes of the process are as follows: the paper is modified with a thiolated capture probe (CP) via Au-S bonds. An aptamer/ignition strand (AP/IS) is designed for specific target recognition. In the presence of peptides, IS is released and this triggers a hybridization chain reaction between two hairpin probes, which can indirectly achieve target detection when the ECL probe $\left(\mathrm{Ru}(\mathrm{phen})_{3}{ }^{2+}\right)$ is introduced into the double-strand DNA grooves, thus producing a significantly amplified ECL signal output.The detection concept is shown in Fig.4(B). This device enables detection of Mucin-1 in a range of $25-50 \mathrm{nM}$ with a detection limit of $8.33 \mathrm{pM}$.
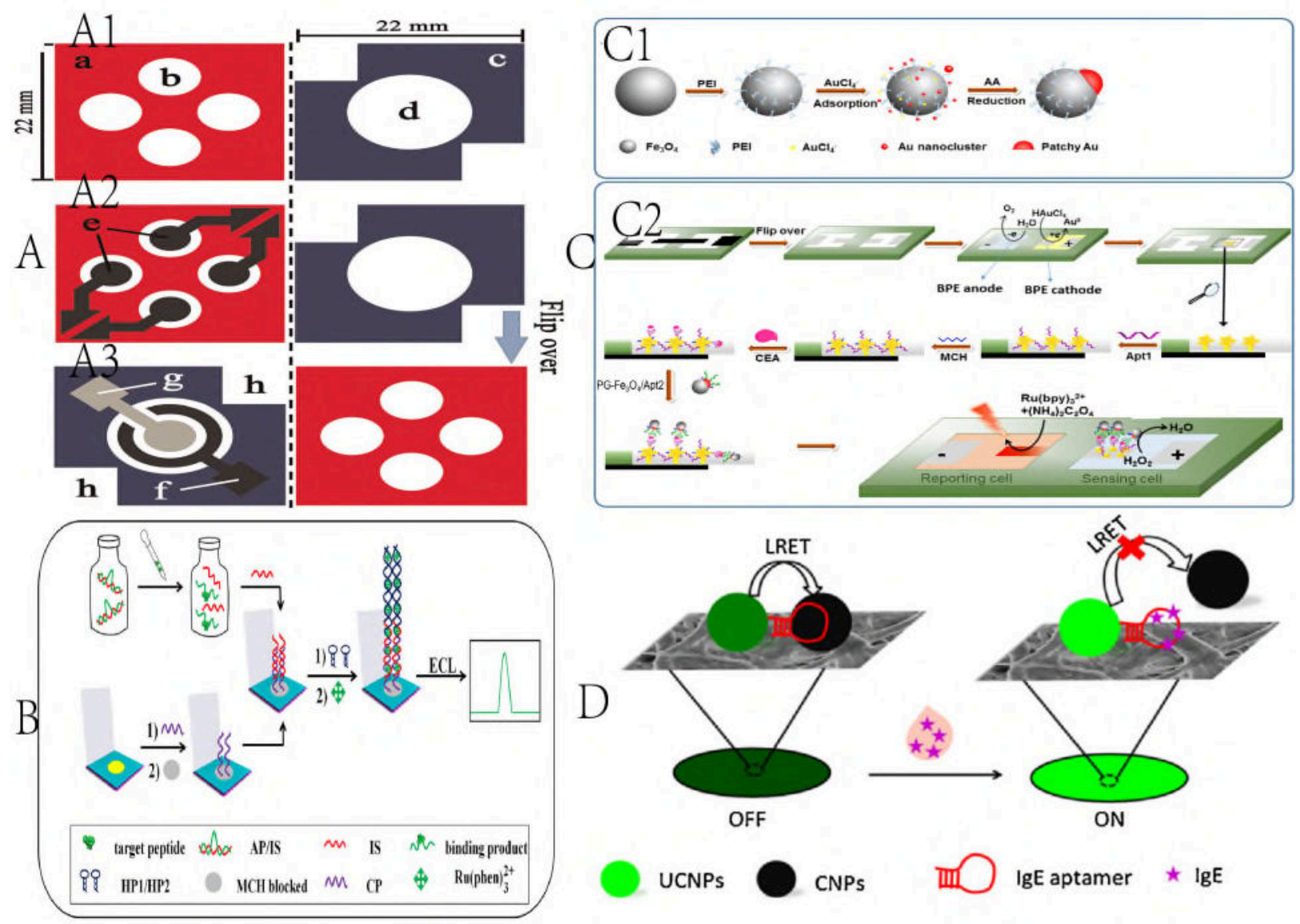

Fig. 4. (A): (A1) Wax patterns of this aptasensor. (A2) The aptasensor with electrode. (A3) The reverse side of (A2) (Wu et al., 2015). (B): Schematic diagram of the aptasensor to detect peptides (Ma et al., 2017). (C): (C1) The synthetic process of PG-Fe3O4 NPs; (C2) Fabrication process of the aptasensor (Zhang et al., 2018). (D): Schematic diagram of the aptasensor (Jiang et al., 2017).

A paper-based bipolar electrode-electrochemiluminescence (pBPE-ECL) aptasensor has been fabricated (Zhang et al., 2018). The detailed synthesis processes of patchy gold coated $\mathrm{Fe}_{3} \mathrm{O}_{4}\left(\mathrm{PG}-\mathrm{Fe}_{3} \mathrm{O}_{4}\right)$ hybrid nanoparticles and aptasensor fabrication are shown in Fig.4(C). The two types of aptamer utilized in CEA detection, are named Apt1 and Apt2. The principle is as follows: Au nanodendrites are electrodeposited onto porous paper at the BPE cathode to supply a favorable matrix for Apt1, which captures CEA. Then PG$\mathrm{Fe}_{3} \mathrm{O}_{4} / \mathrm{Apt} 2$ is captured by the immobilized CEA, thus being attached to the BPE cathode surface and catalyzes $\mathrm{H}_{2} \mathrm{O}_{2}$ reduction to enhance the corresponding ECL emission at the anode. This aptasensor enables detection in 
a range of 0.1-15 $\mathrm{ng} \mathrm{mL}^{-1}$ with an ultra-low detection limit of $0.03 \mathrm{pg} \mathrm{mL}^{-1}$.

\subsubsection{Other optical signal-based paper-based aptasensors}

There are other optical methods that have been used to develop aptasensors. For example, a luminescence resonance energy transfer (LRET) protocol was adopted to develop a paper-based aptasensor to detect IgE (Jiang et al., 2017). The principle is as follows: the $\pi-\pi$ stacking interaction between the aptamer and carbon nanoparticles (CNPs) causes upconversion nanoparticles (UCNPs) and CNPs to move close to each other, thus inducing LRET on the surface, leading to luminescence quenching of UCNPs. Upon exposured to IgE, recognition between the aptamer and IgE inhibits energy transfer, leading to recovery of UCNPs luminescence. The basic concept is shown in Fig.4(D). This aptasensor enables detection with a linear range of $0.5-80 \mathrm{ng} \mathrm{mL}$ -1 .

In summary, many optical detection methods, including colorimetry, fluorescence, SERS, and chemiluminescence, are widely adopted for aptasensors development. Thus far, colorimetry has been the most widely used technique. Fluorescence is widely used for its visualization capabilities and portability. Because of their broad calibration ranges and simple instrumentation systems, SERS, luminescence (Z. Zhang et al., 2019), and chemiluminescence have also are been applied.

\section{2. $\quad$ Paper-based electrochemical aptasensors}

A paper-based electrochemical aptasensor is a small device that converts a chemical quantity of targets into an electrical signal (Saei et al., 2013). Paper-based electrochemical aptasensors have gained extensive attention because of their excellent characteristics, including low power consumption, high portability, high selectivity and sensitivity. Compared to optical aptasensors, electrochemical aptasensors have excellent potential to achieve POC diagnosis because of their ability to quantitively detect targets (Su et al., 2015). In recent years, many paper-based electrochemical aptasensors have been proposed via differential pulse voltammetry (DPV), electrochemical impedance spectroscopy (EIS),etc (Graybill and Bailey, 2016). We classify these aptasensors based on their electrochemical signals (Table 2).

\subsubsection{Paper-based DPV electrochemical aptasensors}

There is an excellent work on developing paper-based DPV electrochemical aptasensor to detect human acute promyelocytic leukemia cells (Su et al., 2014). The principle is as follows: the three-dimensional macroporous Au-paper electrode is modified with aptamers to capture HL-60. Horseradish peroxidase labeled folic acid (HRP-FA) can bind to the captured HL-60 via recognition of FA and folate receptors on the cell surface, and can catalyze oxidation of o-PD by $\mathrm{H}_{2} \mathrm{O}_{2}$, thus forming a reduction peak. A schematic of this aptasensor is shown in Fig.5(A). This device enables detection in a range of $5.0 \times 10^{2}-7.5 \times 10^{7}$ cells $\mathrm{mL}^{-1}$ with a detection limit of 350 cells $\mathrm{mL}^{-1}$.

Another electrochemical aptasensor was proposed to detect hemoglobin A1c (HbA1c) (Shajaripour Jaberi et al., 2019). A paper graphite sheet electrode is modified using a nanocomposite of reduced graphene oxide and gold with a hierarchical architecture structure via electrochemical deposition to improve electron transfer and immobilize aptamers. Interaction between targets and aptamers decreases the current. A simplified fabrication and recognition process are shown in Fig.5(B). A wide linear range of 1-13.83 $\mu \mathrm{M}$ and a low detection limit of $1 \mathrm{nM}$ are achieved.

Our experiments developed a folding label-free electrochemical aptasensor to detect estradiol (Ming et al., 2019). Amine-functionalized single-walled carbon nanotube/new methylene blue/AuNPs are synthesized and coated on the working electrode to increase its detection sensitivity and immobilize the aptamer. The principle is based on a decrease in current that occurs when the aptamer and target combine. The schematic is shown in Fig.5(C). A wide linear range of 10-500 $\mathrm{ng} \mathrm{mL}^{-1}$ and a limit detection of $5 \mathrm{pg} \mathrm{mL}^{-1}$ are achieved. 
Yang Wang and coworkers developed a multi-parameter aptasensor to detect CEA and neuron specific enolase (NSE) simultaneously (Y. Wang et al., 2019). The device performed sample filtration and automatic sample injection through a microfluidic channel and paper matrix. Amino functional graphene/thionine/AuNPs and Prussian blue/poly(3,4-ethylenedioxythiophene)/AuNPs nanocomposites were synthesized to modify the working electrode in order to improve the electron-transfer rate and immobilize aptamers. A schematic diagram of the aptasensor is shown in Fig.6(A). This aptasensor enables detection of CEA and NSE in ranges of 0.01$500 \mathrm{ng} \mathrm{mL} \mathrm{m}^{-1}$ and $0.05-500 \mathrm{ng} \mathrm{mL}^{-1}$, with a detection limit of $2 \mathrm{pg} \mathrm{mL}^{-1}$ and $10 \mathrm{pg} \mathrm{mL}^{-1}$, respectively.

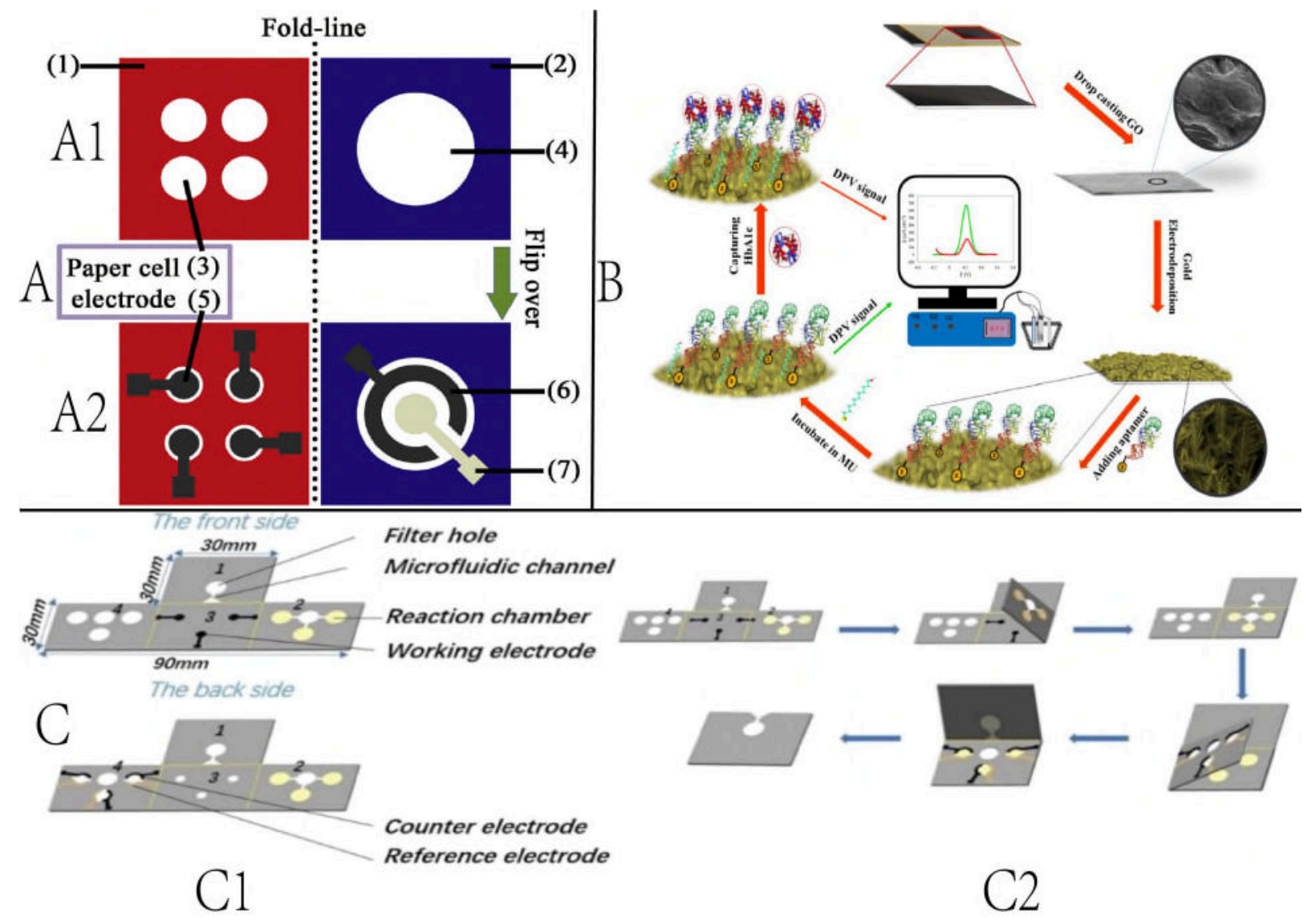

Fig. 5. (A): (A1) Aptasensor wax patterns. (A2) the electrodes on the reverse side of (A1) (Su et al., 2014); (B) The aptasensor modification process (Shajaripour Jaberi et al., 2019). (C) Schematic of the aptasensor; (C1) An aptasensor overview; (C2) the aptasensor folding process. Reprinted with permission from Ming et al., 2019. Copyright (2019) American Chemical Society.

Another electrochemical aptasensor was proposed for sensitive PSA detection (Wei et al., 2018). AuNPs/reduced graphene oxide/thionine nanocomposites were synthesized. The principle is that interaction between targets and aptamers decreases the current. A schematic of the aptasensor is shown in Fig.6(B). A linear range between 0.05 and $200 \mathrm{ng} \mathrm{mL}^{-1}$ and a detection limit of $10 \mathrm{pg} \mathrm{mL}^{-1}$ are achieved in this work.

A general electrochemical sensing platform based on signal molecule-labeled, DNA-modified paper and a target recognition scheme that could detect a variety of biomarkers was proposed (X. Liu et al., 2019). Its principle is as follows: the CEA-designed self-blocked hairpin probe (HP2, containing the CEA aptamer sequence) can bind to CEA. This exposed the occluded stem region. The exposed region can hybridize with another rationally designed ssDNA probe to initiate the subsequent polymerization/indentation reaction, which forms a DNAzyme chain. The released DNAzyme chain generates an amplified signal response. A schematic illustration of the principle of the detection is shown in Fig.6(C). 


\subsubsection{Paper-based electrochemical aptasensor using other signals}

A paper-based EIS aptasensor was proposed for CEA detection (Yen et al., 2020). After modification with graphene/poly(3,4 ethylenedioxythiophene):poly(styrenesulfonate), the conductivity of the paper electrode was enhanced, thus providing a sensitive substrate for aptamers immobilization. The detection principle is that formation of aptamer-antigen complexes on the electrode surface would lead to corresponding resistance changes. This aptasensor was capable of detecting CEA in a range of 0.76-14 $\mathrm{ng} \mathrm{mL}-1$ with a detection limit of is $0.45 \mathrm{ng} \mathrm{mL}-1$.
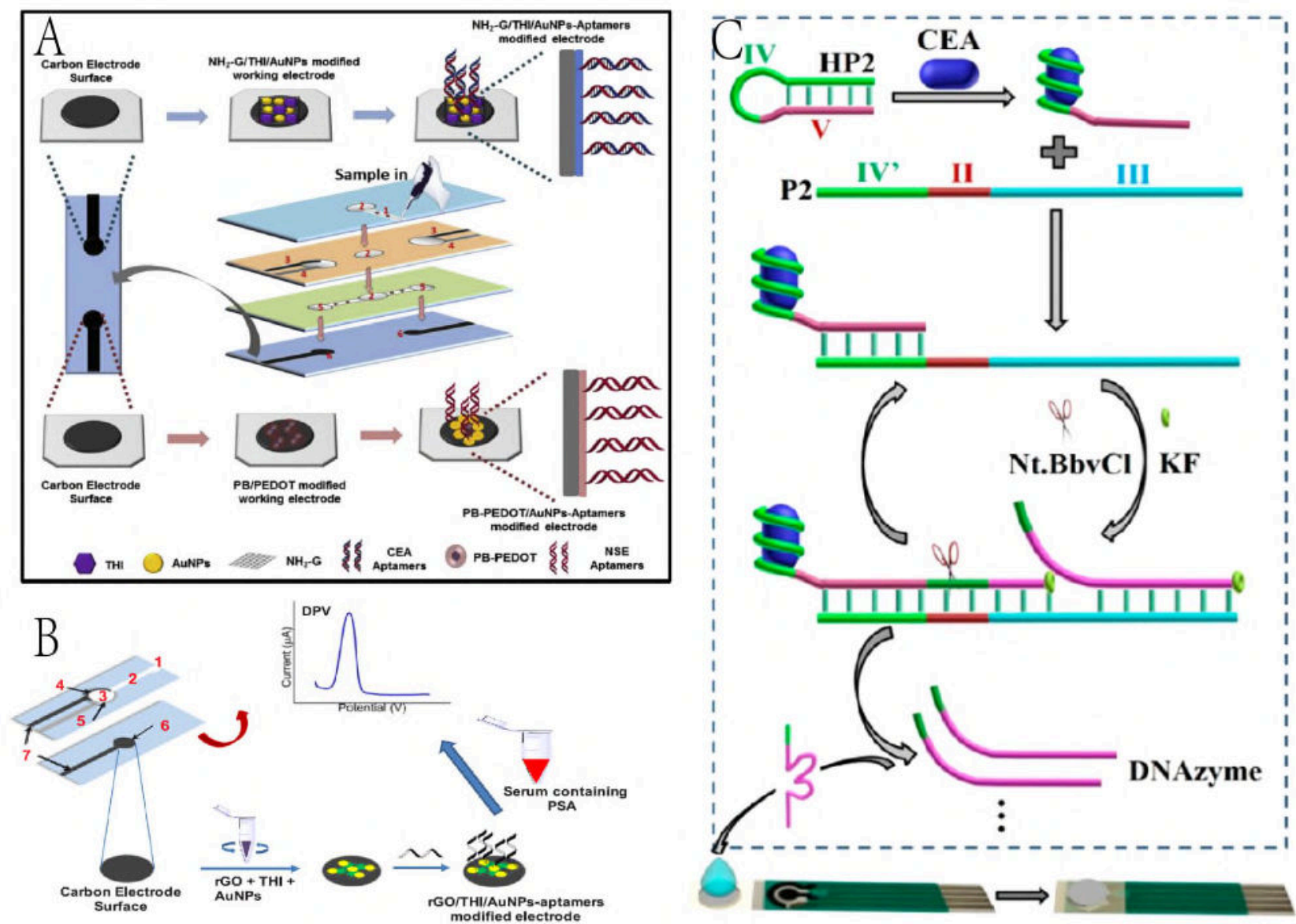

Fig. 6. Schematic diagrams of the aptasensors; (A) The aptasensor preparation and modification process (Y. Wang et al., 2019); (B) The aptasensor manufacturing and modification process (Wei et al., 2018); (C) Schematic diagram of the CEA assay. Reprinted with permission from X. Liu et al., 2019. Copyright (2019) American Chemical Society.

Photoelectrochemical (PEC) analysis is a rapidly developing method. High-precision, high-sensitivity detection is achieved using simple equipment and suitable photosensitive materials (Huang et al., 2020).

A photoelectrochemical sensing platform was proposed to detect thrombin (TB) (Xue et al., 2019). The detection principle is as follows: In the presence of TB, hairpin DNA1 (HP1, containing TB aptamer) can combine with TB to form HP1@TB, which can then hybridize with magnetic beads-HP2, After the formed complex is digested by Nt.AlwI, a large quantity of secondary tDNA is released for further hybridization reactions and the released HP1@TB is subject to new cyclic cleavage. The result is effective target signal conversion and amplification. After $\mathrm{CeO}_{2}$-labeled hairpin DNA3 $\left(\mathrm{CeO}_{2}-\mathrm{HP} 3\right)$ is anchored on the surfaces of paper-based $\mathrm{TiO}_{2}$ nanosheets (PTNs), the photocurrent intensity is greatly enhanced. Numerous secondary tDNA pieces can hybridize with $\mathrm{CeO}_{2}-\mathrm{HP} 3$ on the electrode surface. This causes $\mathrm{CeO}_{2}$ to leave the PTNs 
surface and leads a significant photocurrent decrease. A device schematic is shown in Fig.7(A). This aptasensor offers a linear range of $0.02-100 \mathrm{pM}$ with a detection limit of $6.7 \mathrm{fM}$.

Fig. 7. Aptasensors schematics; (A) Schematic diagram of the $\mu$-PEC sensing platform. (A1) The TB

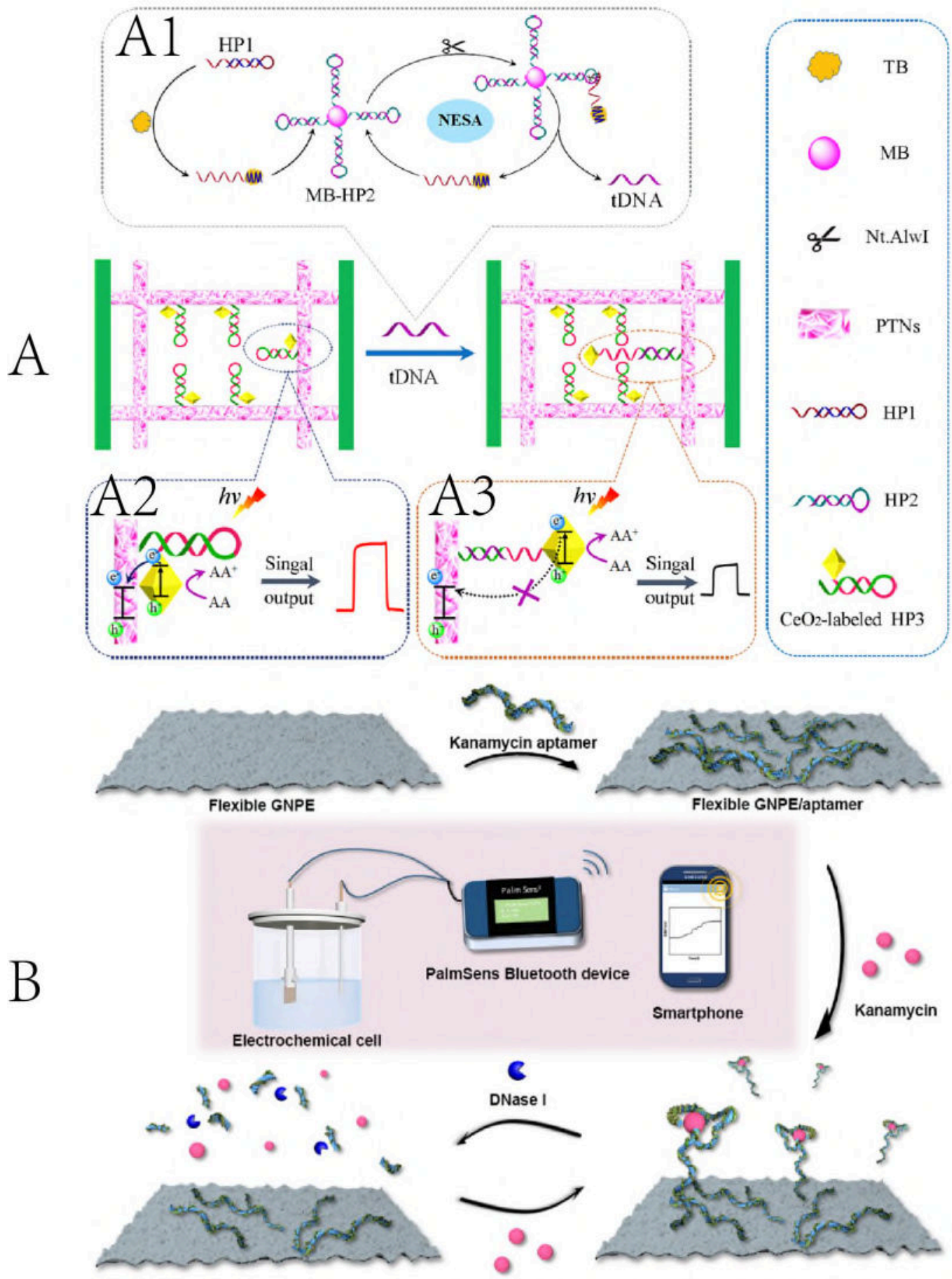

recognition process and target-triggering procedure. (A2) The immobilization mechanism of $\mathrm{CEO}_{2}$-labeled HP3 on PTNs/paper electrode and the generation mechanism of photocurrent. (A3) The photocurrent-decrease mechanism (Xue et al., 2019); (B)Schematic of a flexible freestanding GNP-based potentiometric enzymatic aptasensor (Yao et al., 2019);

A wide-spectrum-responsive $\mathrm{PEC}$ aptasensor based on $\mathrm{TiO}_{2} /$ black phosphorus quantum dots $\left(\mathrm{TiO}_{2}-\mathrm{BPQDs}\right)$ was proposed for PSA detection (Shi et al., 2019). The principle is as follows: $\mathrm{TiO}_{2}$ was synthesized on the paper and $\mathrm{TiO}_{2}-\mathrm{BPQDs}$ formed upon BPQDs addition to capture DNA. 
The AuNPs-modified aptamer could be immobilized via hybridization with the captured DNA. Excitonplasmon interactions between $\mathrm{TiO}_{2}-\mathrm{BPQDs}$ and AuNPs could deeply attenuate and even absolutely damp the photocurrent (B. Yang et al., 2017). Upon adding PSA, the aptamer would dissociate from the electrode, leading to photocurrent recovery. A linear range of $0.005-50 \mathrm{ng} \mathrm{mL}^{-1}$ with a detection limit of $1 \mathrm{pg} \mathrm{mL}^{-1}$ are achieved in this work.

In addition, a potentiometric aptasensor based on flexible freestanding graphene paper was proposed to detect kanamycin (Yao et al., 2019). The principle is as follows: aptamers can bond to the surface of a graphene paper electrode (GNPE) via $\pi-\pi$ stacking and nuclease cleavage is avoided due to hydrophobic interactions between the aptamers and graphene. When aptamers binds to targets, it desorbs from GNPE surface and tends to separate its negatively ionized phosphodiester groups. This charge variation causes a subsequent change in the recorded potential values. The free aptamer is cleaved by the unimmobilized nuclease in the detection cell, thus releasing the kanamycin molecules. The released targets can hybridize with new aptamers on the GNPE surface and initiate a new cleavage cycle, which leads to a target recycling process. This leads to a significant signal amplification and greatly improves detection sensitivity. A schematic of the aptasensor is shown in Fig.7(B). The aptasensor enables detection linear ranges of 0.03-20 pg mL $\mathrm{mL}^{-1}$ and 20-150 $\mathrm{pg} \mathrm{mL}^{-1}$ with a detection limit of $30.0 \mathrm{fg} \mathrm{mL}^{-1}$.

\subsubsection{Paper-based aptasensor using dual-mode signals}

Some paper-based aptasensors use dual-mode signals to detect biomarkers. Dual-mode signals widen the aptasensor application range, and dual-mode results can be mutually complementary and thus more accurate.

A great paper-based dual-mode aptasensor was developed to simultaneous perform electrical and colorimetric detection (Wang et al., 2018). The principle is as follows: the paper working electrode (PWE) is modified with in-situ synthesized three dimensional reduced graphene oxide (3D-rGO) and AuNPs. The fabricated Au@3D-rGO/PWE can capture MCF-7 cells after it is combined with aptamer1. Also, polyhedral AuPd alloy nanoparticles (PH-AuPd NPs) combine with aptamer2 and are immobilizzed on the captured MCF7 cells. $\mathrm{H}_{2} \mathrm{O}_{2}$ can be catalyzed by $\mathrm{PH}-\mathrm{AuPd}$ NPs to generate $\bullet \mathrm{OH}$, resulting in an amplified electrochemical signal. Meanwhile, the generated $\bullet \mathrm{OH}$ can transfer outward to the colorimetric detection zone so as to produce a colorimetric signal. The schematic of the aptasensor is shown in Fig.8(A). This device enables a linear detection range of $50-10^{7}$ cells $\mathrm{mL}^{-1}$ with a detection limit of 20 cells $\mathrm{mL}^{-1}$.

The three-dimensional structures of another dual-mode aptasensor is shown in Fig.8(B) (Li et al., 2019). Six layers are stacked vertically from top to bottom. Electrochemical detection is performed in the upper three layers. Au-modified paper working electrode (TSAu-PWE) can fix the aptamer (S1) on its surface. The complementary DNA strand, labeled with methylene blue (MB), is immobilized onto TSAu-PWE via hybridization. The DNA strand is released in the presence of target cells. S1-labeled cubic dendritic hollow Pd-Pt nanoparticles (CDH-Pd-Pt NPs) that are loaded with ferrocene $(\mathrm{Fc})$ are linked onto TSAu-PWE, resulting in an increased $\mathrm{Fc} / \mathrm{MB}$ current intensity ratio. Then, $\mathrm{H}_{2} \mathrm{O}_{2}$ is added to the paper via the colormetric injection port. Upon introducing of more cells, more CDH-Pd-Pt NPs are linked to TSAu-PWE, resulting in increased consumpution of $\mathrm{H}_{2} \mathrm{O}_{2}$ and decreased consumption of the sealing reagent (AgNPs). Therefore, the distance that the fluid in the transport layer can move becomes shorter. Once the fluid is transported from left to right through the lower transport layer, the white areas on the chromogenic layer are connected to each other. Therefore, the cell concentration can be calculated based on the distance that the liquid moves. This aptasensor enables detection of MCF-7 and K562 cells in wide ranges of $150-1.0 \times 10^{7}$ and $220-7.0 \times 10^{6}$ cells $\mathrm{mL}^{-1}$. The detection limits were 117 and 140 cells $\mathrm{mL}^{-1}$, respectively.

Taking the pop-up structure as mechanical value, a dual-mode aptasensor with a DPV/super capacitor amplification signal readout system was realized (Liu et al., 2020). The principle is as follows: AuNPs are 
Table.2: A list of the paper-based electrochemical microfluidic aptasensors

\begin{tabular}{|c|c|c|c|c|c|}
\hline Signal & $\begin{array}{l}\text { Number of } \\
\text { Biomarkers }\end{array}$ & Nanomatrial & Linear Range & LOD & Reference \\
\hline DPV & 4 & Macroporous Au & $\begin{array}{l}5 \times 10^{2}-7.5 \times 10^{7} \text { cell } \\
\mathrm{mL}^{-1}\end{array}$ & $\begin{array}{l}350 \text { cell } \\
\mathrm{mL}^{-1}\end{array}$ & $\begin{array}{l}\text { (Su et al., } \\
2014 \text { ) }\end{array}$ \\
\hline DPV & 1 & $\begin{array}{l}\text { Reduced graphene } \\
\text { oxide/ AuNPs }\end{array}$ & $0.001-13.83 \mu \mathrm{M}$ & $1 \mathrm{nM}$ & $\begin{array}{l}\text { (Shajarip } \\
\text { our Jaberi } \\
\text { et al., } \\
\text { 2019) }\end{array}$ \\
\hline DPV & 3 & $\begin{array}{l}\text { Single-walled } \\
\text { carbon } \\
\text { nanotube/AuNPs }\end{array}$ & $0.01-500 \mathrm{ng} \mathrm{mL}^{-1}$ & $5 \mathrm{pg} \mathrm{mL}^{-1}$ & $\begin{array}{l}\text { (Ming et } \\
\text { al., 2019) }\end{array}$ \\
\hline DPV & 2 & Graphene/AuNPs & $\begin{array}{l}0.01-500 \mathrm{ng} \mathrm{mL}^{-1} \\
0.05-500 \mathrm{ng} \mathrm{mL}^{-1}\end{array}$ & $\begin{array}{l}2 \mathrm{pg} \mathrm{mL}^{-1} \\
10 \mathrm{pg} \mathrm{mL}^{-1}\end{array}$ & $\begin{array}{l}\text { (Y. Wang } \\
\text { et al., } \\
\text { 2019) }\end{array}$ \\
\hline DPV & 1 & $\begin{array}{l}\text { Reduced graphene } \\
\text { oxide/ AuNPs }\end{array}$ & $0.05-200 \mathrm{ng} \mathrm{mL}^{-1}$ & $10 \mathrm{pg} \mathrm{mL}^{-1}$ & $\begin{array}{l}\text { (Wei et } \\
\text { al., 2018) }\end{array}$ \\
\hline DPV & 1 & - & $0.001-1.5 \mathrm{pg} \mathrm{mL}^{-1}$ & $1 \mathrm{fg} \mathrm{mL}^{-1}$ & $\begin{array}{l}\text { (X. Liu et } \\
\text { al., 2019) }\end{array}$ \\
\hline EIS & 1 & $\begin{array}{l}\text { Graphene/PEDOT:P } \\
\text { SS }\end{array}$ & $0.76-14 \mathrm{ng} \mathrm{mL}^{-1}$ & $\begin{array}{l}0.45 \mathrm{ng} \\
\mathrm{mL} L^{-1}\end{array}$ & $\begin{array}{l}\text { (Yen et } \\
\text { al., 2020) }\end{array}$ \\
\hline $\begin{array}{l}\text { Photoelectroch } \\
\text { emical }\end{array}$ & 1 & $\mathrm{TiO}_{2}$ & $0.02-100 \mathrm{pM}$ & $6.7 \mathrm{fM}$ & $\begin{array}{l}\text { (Xue et } \\
\text { al., 2019) }\end{array}$ \\
\hline $\begin{array}{l}\text { Photoelectroch } \\
\text { emical }\end{array}$ & 1 & AuNPs & $0.005-50 \mathrm{ng} \mathrm{mL}^{-1}$ & $1 \mathrm{pg} \mathrm{mL}^{-1}$ & $\begin{array}{l}\text { (Shi et al., } \\
\text { 2019) }\end{array}$ \\
\hline Potentiometric & 1 & Graphene & $\begin{array}{l}0.03 \times 10^{-3}-0.02 \text { and } \\
0.02-0.15 \mathrm{ng} \mathrm{mL}^{-1}\end{array}$ & $\begin{array}{l}0.03 \mathrm{pg} \\
\mathrm{mL}-1\end{array}$ & $\begin{array}{l}\text { (Yao et } \\
\text { al., 2019) }\end{array}$ \\
\hline $\begin{array}{l}\text { Dual-mode } \\
\text { signals }\end{array}$ & 1 & $\begin{array}{l}\text { Polyhedral AuPd } \\
\text { alloy } \\
\text { nanoparticles/AuN } \\
\text { Ps }\end{array}$ & $50-10^{7}$ cells $\mathrm{mL}^{-1}$ & $\begin{array}{l}20 \text { cells } \\
\mathrm{mL}^{-1}\end{array}$ & $\begin{array}{l}\text { (Wang et } \\
\text { al., 2018) }\end{array}$ \\
\hline $\begin{array}{l}\text { Dual-mode } \\
\text { signals }\end{array}$ & 2 & $\begin{array}{l}\text { Cubic dendritic } \\
\text { hollow Pd-Pt } \\
\text { nanoparticles }\end{array}$ & $\begin{array}{l}150-1 \times 10^{7} \text { and } \\
220-7 \times 10^{6} \text { cells } \\
\mathrm{mL}^{-1}\end{array}$ & $\begin{array}{l}117 \text { and } \\
140 \text { cells } \\
\mathrm{mL}^{-1}\end{array}$ & $\begin{array}{l}\text { (Li et al., } \\
\text { 2019) }\end{array}$ \\
\hline $\begin{array}{l}\text { Dual-mode } \\
\text { signals }\end{array}$ & 1 & AuNPs & $10-5000 \mathrm{nM}$ & $1.4 \mathrm{nM}$ & $\begin{array}{l}\text { (Liu et al., } \\
2020 \text { ) }\end{array}$ \\
\hline $\begin{array}{l}\text { Dual-mode } \\
\text { signals }\end{array}$ & 2 & $\begin{array}{l}\text { Reduced graphene } \\
\text { oxide }\end{array}$ & & $\begin{array}{l}10 \mu \mathrm{M} \\
3 \mathrm{nM}\end{array}$ & $\begin{array}{l}\text { (Hui et al., } \\
\text { 2018) }\end{array}$ \\
\hline
\end{tabular}

grown in-situ in the detection zone. A sandwich comprising a DNA sequence (DNA1), the aptamer and glucose oxidase modified DNA sequence (GOx-DNA2) is formed in the detection zone via hybridization, thus 
achieving supercapacitor detection. After adding ATP, binding of ATP to the aptamer releases GOx-DNA2, which can enter the reaction zone to catalyze glucose oxidation. Because of the different

$\left[\mathrm{Fe}(\mathrm{CN})_{6}\right]^{3-}$ and $\left[\mathrm{Fe}(\mathrm{CN})_{6}\right]^{4-}$ concentrations generated by the GOx-triggered reaction, a voltage can be generated to charge a paper supercapacitor. It can provide a high instantaneous current to a digital multimeter to visualize the analysis results and achieve self-generation of amplified electrical signals. By changing the
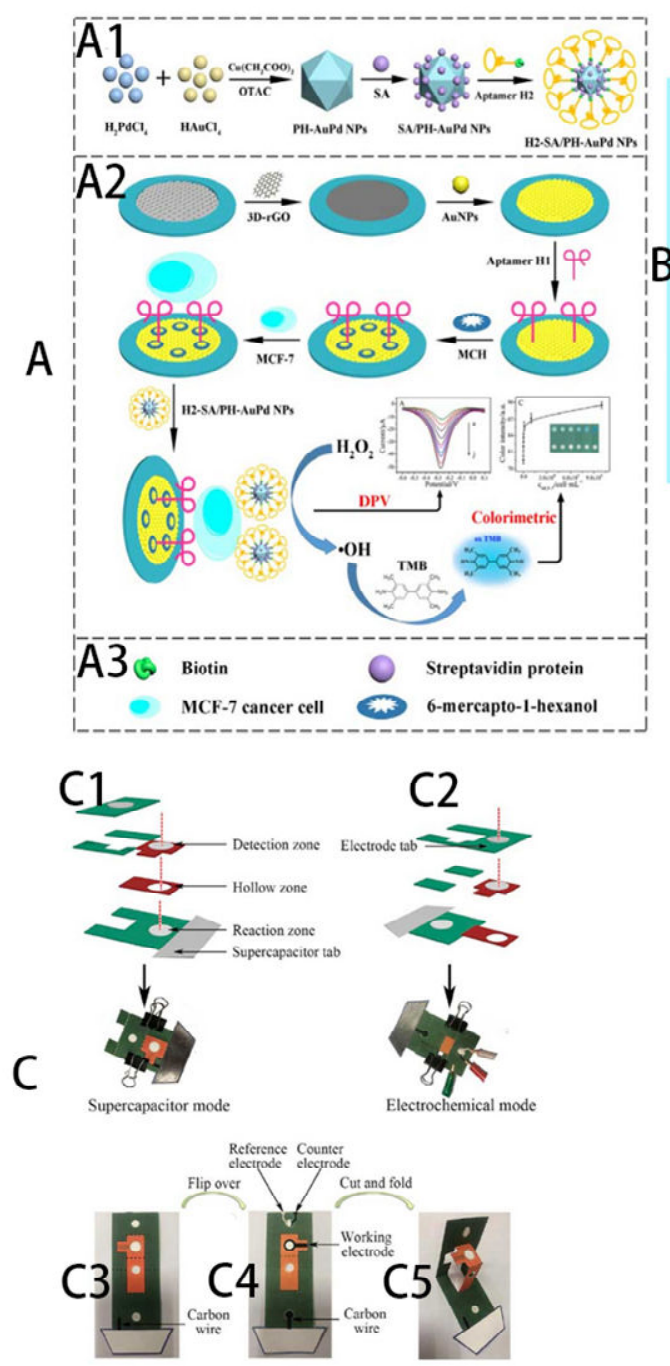

B1
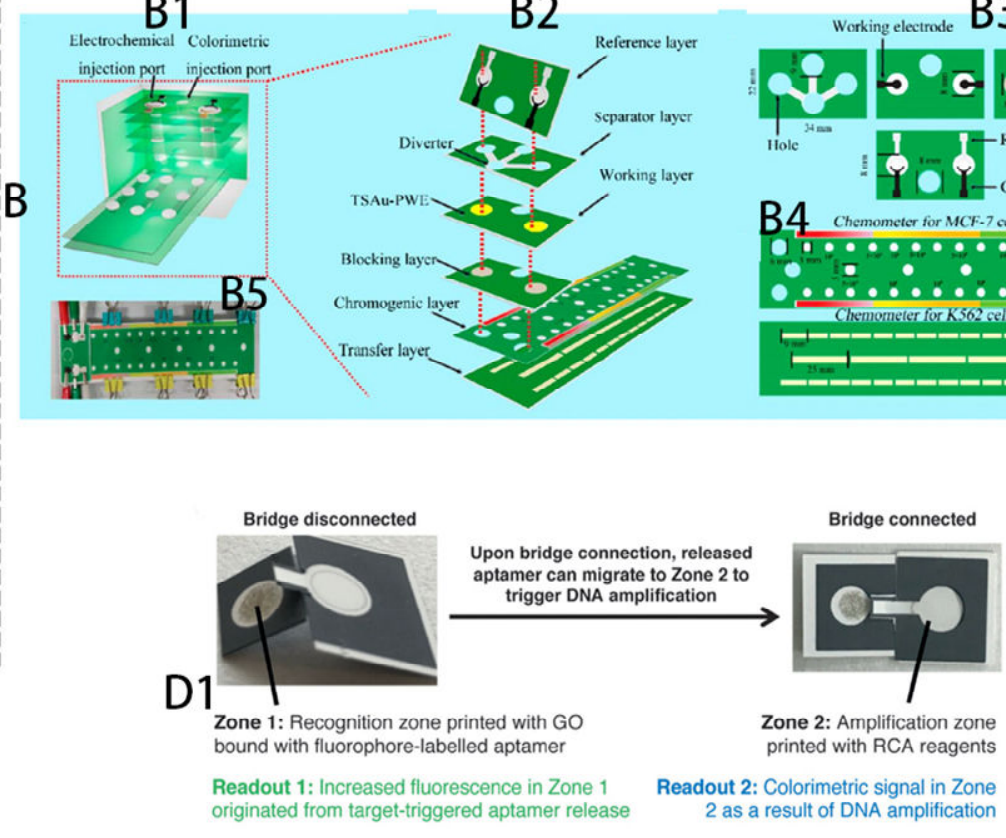

D
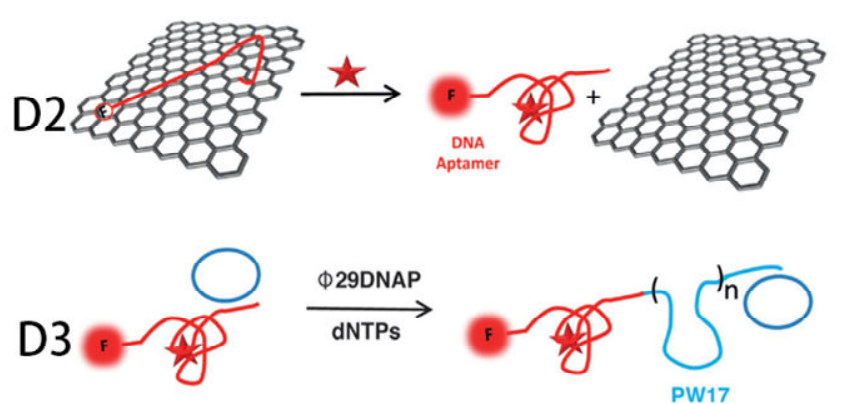

Fig. 8. Dual-mode aptasensor schematics. (A): The dual-mode cytosensor fabrication process: (A1) The H1SA/PH-AuPd NPs manufacturing process; (A2) the detection principle (Wang et al., 2018). (B): (B1) Threedimensional aptasensor structures. (B2) enlarged schematic diagram; (B3, B4) size of each parts; (B5) physical figure. Reprinted with permission from Li et al., 2019. Copyright (2019) American Chemical Society.; (C): $(\mathrm{C} 1, \mathrm{C} 2)$ Schematic and physical figure of the aptasensor; (C3-C5) Schematic of aptasensor with electrodes (Liu et al., 2020). (D): Schematic of the aptasensor (Hui et al., 2018).

direction of the pop-up structure, a DPV readout mode electrochemical signal can be produced via glucose catalytic oxidation by the remaining GOx-DNA2 on the detection zone. The analytical procedures are shown in Fig.8(C). This device enables detection in a linear range of 10-5000 $\mathrm{nM}$ with a detection limit of $3 \mathrm{nM}$ and $1.4 \mathrm{nM}$.

In addition, a delicate, paper-based aptasensor platform was proposed for molecular recognition and signal 
amplification (Hui et al., 2018). The schematic is shown in Fig.8(D). The platform consists of two reaction zones and a connecting bridge, and uses multifunctional biological/nanomaterials to achieve molecular recognition and signal amplification. After the analyte is added to Zone 1, the fluorescent-labeled aptamer can desorb from the printed graphene oxide to quickly generate the initial fluorescence signal. The released aptamer then flows to Zone 2, where it reacts with printing reagents to initiate roll loop amplification. There, it produces DNA amplicons that contain a peroxidase-mimicking DNAzyme, resulting in a colorimetric signal.

\section{Conclusion and future perspectives}

Although many paper-based microfluidic aptasensors with broad application prospects for the detection of cancers, pathogens, infectious diseases, hormones have been proposed, several important issues remain to be resolved before they can become competitive in the POC diagnosis market.

Presently, substantial literatures mainly focus on developing aptasensors that can detect a wide range of biomarkers with low detection limits. However, because of the high sensitivity of paper-based aptasensors, special attention should be paid to the possibility of false positive due to small non-specific adsorption. The deterioration of the paper quality after long-term storage will also affect the performance of the sensor, which also requires further improvement. And aptamers binding with targets may also be affected due to the complex environment and interferences in biological samples. In addition, the portability, ease-of-use, and the cost, etc. should also be taken into account before they become reliable industrial products.

Therefore, more efforts should be dedicated to four subjects: 1) Screening of aptamers. Bodily fluids contain many interfering materials that might affect combinations of aptamers with target biomarkers. Aptamers must become more specific and stable in order to remain selective and sensitive when complex interferences sources are present. Also, there are still many biomarkers of critical importance that do not have corresponding aptamers of high affinity and specificity, which fundamentally limits the development and application of paper-based microfluidic aptasensors. Therefore, when choosing aptamers, researchers should not only focus on the dissociation constants, but also consider its stability and specificity. The possible interfering substances in blood, sweat and urine are also different. Researchers should first consider which body fluid they are in when detecting biomarkers, and then select the appropriate aptamer according to the specific situation. For those important biomarkers that lack corresponding aptamers, researchers should make more efforts to synthesize corresponding aptamers. 2) Nanomaterials selection and synthesis. Nanomaterials play an important role in aptasensor development. They also largely determine aptasensor performance and stability. However, when analyzing real samples, there are many interferences that can affect performance and, greatly affect the detection accuracy. Therefore, researchers should consider possible effects in body fluids when selecting materials. For example, in the preparation of optical sensors, if it is necessary to detect markers in thicker-colored body fluids, materials that can produce high-penetrating light will be more suitable. In the preparation of electrochemical sensors, if the influence of body fluids is too great, materials similar to chitosan may be needed to form thin films at the expense of high sensitivity to reduce the influence of body fluids on electrical signal. 3) Device design. It is unacceptable for multiple manual steps to be involved in the use of aptasensors for detection or for a complex architecture to be required. These disadvantages will hinder device use and increase production costs. To be used widely in poor areas with limited resources or in patient's homes, the device should be an integrated system with complete functionality that requires a few extremely simple operations and the cost of each analysis should be low. Therefore, when designing the structures, researchers need to consider the practicability of the application, and simplify the operation steps as much as possible while ensuring the integration of all the required functional components. Ease of use is our primary pursuit, followed by production costs, and finally the exquisite and beautiful structure. 4) Paper-based microfluidic aptasensors must be fully integrated with small portable devices or wearable devices, as integrating aptasensors into 
microsystems or portable tools can facilitate aptasensor-based field detection and eliminates the need for large chemical stations. Combining aptasensors with wearable devices can also meet the needs of many diseases that require detection of certain markers for a period of time. Also, integration of paper-based aptasensor with small portable devices/wearable devices will bring the potential of sensor portability and cheapness to full play. For example, when combining paper-based aptasensors with portable meter as signal output, the sensitive and cheap detection can be exhibited in any remote areas. Moreover, abundant remote medical resources can also be used when portable meter is connected with a smart phone: users can send the results obtained by the portable meter to the remote professionals, and any related doubts can be solved immediately. To achieve this goal, sensor developers and portable device developers should cooperate with each other. In terms of structure, the connection interface between the two should be simple and stable. When choosing nanomaterials, make sure that the generated signal data can be collected and processed. Of course, in order not to affect the widespread application of portable device, its cost should not be too high, and its operation should be simple and easy to understand.

We believe that pursuing the above four efforts will produce aptasensors that perform better in specificity, stability, sensitivity, robustness, reusability, ease of use, portability and reproducibility, such that they eventually become the first choice for residents to accurately detect biomarkers at home or in other resourcepoor areas, or even replace large-scale instruments and become the first choice for hospitals. The ultimate purpose of POC diagnosis is to transfer the medical detection and monitoring process from the hospital to the patients' home so that everyone can enjoy the most comprehensive, inexpensive health maintenance via systems that consume few resources and operate simply. We firmly believe that paper-based microfluidic aptasensors can achieve this goal in the near future.

\section{Acknowledgements}

This work is sponsored by the NSFC (61960206012,61527815,81971348,61673024,61771452 and 61775216), China; the National Key Research and Development Program (2017YFA0205902), China; the Key Research programs (QYZDJ-SSW-SYS015) of Frontier Sciences, CAS, China. 


\section{Reference}

Akyazi, T., Basabe-Desmonts, L., Benito-Lopez, F., 2018. Anal. Chim. Acta 1001, 1-17.

Aldewachi, H., Chalati, T., Woodroofe, M.N., Bricklebank, N., Sharrack, B., Gardiner, P., 2018. Nanoscale 10, 18-33.

Alsager, O.A., Kumar, S., Zhu, B., Travas-Sejdic, J., McNatty, K.P., Hodgkiss, J.M., 2015. Anal. Chem. 87, 4201-4209.

Alshaer, W., Hillaireau, H., Vergnaud, J., Mura, S., Deloménie, C., Sauvage, F., Ismail, S., Fattal, E., 2018. J. Control.

Release 271, 98-106.

Bezinge, L., Suea-Ngam, A., Demello, A.J., Shih, C.J., 2020. Mol. Syst. Des. Eng. 5, 49-66.

Bilibana, M.P., Citartan, M., Yeoh, T.S., Rozhdestvensky, T.S., Tang, T.-H., 2017. J. Nucleic Acids 2017, 3712070.

Cao, Liangli, Fang, C., Zeng, R., Zhao, X., Zhao, F., Jiang, Y., Chen, Z., 2017. Sensors Actuators B Chem 252, 44-54.

Carlson-Stevermer, J., Abdeen, A.A., Kohlenberg, L., Goedland, M., Molugu, K., Lou, M., Saha, K., 2017. Nat. Commun. $8,1711$.

Carvalho, W.S.P., Wei, M., Ikpo, N., Gao, Y., Serpe, M.J., 2018. Anal. Chem. 90, 459-479.

Chen, L., Choo, J., 2008. Electrophoresis 29, 1815-1828.

Chin, C.D., Linder, V., Sia, S.K., 2012. Lab Chip 12, 2118-2134.

Choi, J.R., Hu, J., Tang, R., Gong, Y., Feng, S., Ren, H., Wen, T., Li, X., Wan Abas, W.A.B., Lab Chip 16, 611-621.

Citartan, M., Ch'ng, E.S., Rozhdestvensky, T.S., Tang, T.H., 2016. Microchem. J. 128, 187-197.

Citartan, M., Tang, T.H., 2019. Talanta 199, 556-566.

Dalirirad, S., Steckl, A.J., 2019. Sensors Actuators B Chem. 283, 79-86.

Devi, P., Thakur, A., Lai, R.Y., Saini, S., Jain, R., Kumar, P., 2019. TrAC Trends Anal. Chem. 110, 97-115.

Dirkzwager, R.M., Liang, S., Tanner, J.A., 2016. ACS Sensors 1, 420-426.

Dolatabadi, J.E.N., Mashinchian, O., Ayoubi, B., Jamali, A.A., Mobed, A., Losic, D., Omidi, Y., de la Guardia, M., 2011.

TrAC Trends Anal. Chem. 30, 459-472.

Du, Y., Dong, S., 2016. Anal. Chem. 189-215.

Economou, A., Kokkinos, C., Prodromidis, M., 2018. Lab Chip 18, 1812-1830.

Eissa, S., Zourob, M., 2017. Biosens. Bioelectron. 91, 169-174.

Ellington, A.D., Szostak, J.W., 1992. Nature 355, 850-852.

Ellington, A.D., Szostak, J.W., 1990. Nature 346, 818-822.

Fakhri, N., Hosseini, M., Tavakoli, O., 2018. Anal. Methods 10, 4438-4444.

Farzin, L., Shamsipur, M., 2018. J. Pharm. Biomed. Anal. 147, 185-210.

Feng, C., Dai, S., Wang, L., 2014. Biosens. Bioelectron. 59, 64-74.

Fleischmann, M., Hendra, P.J., McQuillan, A.J., 1974. Chem. Phys. Lett. 26, 163-166.

Fu, L.-M., Wang, Y.-N., 2018. TrAC Trends Anal. Chem. 107, 196-211.

Geldert, A., Kenry, Lim, C.T., 2017. Sci. Rep. 7, 17510.

Golub, E., Pelossof, G., Freeman, R., Zhang, H., Willner, I., 2009. Anal. Chem. 81, 9291-9298.

Gong, M.M., Sinton, D., 2017. Chem. Rev. 117, 8447-8480.

Graybill, R.M., Bailey, R.C., 2016. Anal. Chem. 88, 431-450.

Gutiérrez-capitán, M., Baldi, A., Fernández-sánchez, C., 2020. Sensors 20(4):967.

Harpaz, D., Eltzov, E., Seet, R.C.S., Marks, R.S., Tok, A.I.Y. Biosensors 2017, 7, 30.

Hay Burgess, D.C., Wasserman, J., Dahl, C.A., 2006. Global health diagnostics. Nature 444, 1-2.

Hu, S.-W., Qiao, S., Pan, J.-B., Kang, B., Xu, J.-J., Chen, H.-Y., 2018. Talanta 179, 9-14.

Huang, Q., Liu, Y., Zhang, C., Zhang, Z., Liu, F., Peng, J., 2020. ACS Omega 5, 8423-8431.

Huang, Z., Hu, S., Xiong, Y., Wei, H., Xu, H., Duan, H., Lai, W., 2019. TrAC Trends Anal. Chem. 114, 151-170.

Hui, C.Y., Liu, M., Li, Y., Brennan, J.D., 2018. Angew. Chemie Int. Ed. 57, 4549-4553.

Jamali, A.A., Pourhassan-Moghaddam, M., Dolatabadi, J.E.N., Omidi, Y., 2014. Trac Trends Anal. Chem. 55, $24-42$. 
Jeanmaire, D.L., Van Duyne, R.P., 1977. J. Electroanal. Chem. Interfacial Electrochem. 84, 1-20.

Jiang, P., He, M., Shen, L., Shi, A., Liu, Z., 2017. Sensors Actuators B Chem. 239, 319-324.

Khoshbin, Z., Housaindokht, M.R., Izadyar, M., Verdian, A., Bozorgmehr, M.R., 2019. Anal. Chim. Acta 1071, 70-77. Lan, Q., Ren, C., Lambert, A., Zhang, G., Li, J., Cheng, Q., Hu, X., Yang, Z., 2020. ACS Sustain. Chem. Eng. 8, $4392-4399$. Li, J.-F., Zhang, Y.-J., Ding, S.-Y., Panneerselvam, R., Tian, Z.-Q., 2017. Chem. Rev. 117, 5002-5069.

Li, L., Chen, Y., Zhu, J.-J., 2017. Anal. Chem. 89, 358-371.

Li, L., Zhang, Y., Ge, S., Zhang, L., Cui, K., Zhao, P., Yan, M., Yu, J., 2019. Anal. Chem. 91, 10273-10281.

Li, Z., Li, F., Xing, Y., Liu, Z., You, M., Li, Y., Wen, T., Qu, Z., Ling Li, X., Xu, F., 2017. Biosens. Bioelectron. 98, $478-485$.

Liang, L., Su, M., Li, L., Lan, F., Yang, G., Ge, S., Yu, J., Song, X., 2016. Sensors Actuators B Chem. 229, 347-354.

Liu, F., Wang, S., Zhang, M., Wang, Y., Ge, S., Yu, J., Yan, M., 2014. Microchim. Acta 181, 663-670.

Liu, X., Li, X., Gao, X., Ge, L., Sun, X., Li, F., 2019. ACS Appl. Mater. Interfaces 11, 15381-15388.

Liu, Y., Cui, K., Kong, Q., Zhang, L., Ge, S., Yu, J., 2020. Biosens. Bioelectron. 148, 111839.

Liu, Y., Tuleouva, N., Ramanculov, E., Revzin, A., 2010. Anal. Chem. 82, 8131-8136.

Ma, C., Liu, H., Zhang, L., Li, L., Yan, M., Yu, J., Song, X., 2017. ChemElectroChem 4, 1744-1749.

Mahadeva, S.K., Walus, K., Stoeber, B., 2015. ACS Appl. Mater. Interfaces 7, 8345-8362.

Mahato, K., Srivastava, A., Chandra, P., 2017. Biosens. Bioelectron. 96, 246-259.

Manz, A., Harrison, D.J., Verpoorte, E.M.J., Fettinger, J.C., Paulus, A., Lüdi, H., Widmer, H.M., 1992. J. Chromatogr. A 593, 253-258.

Mao, K., Min, X., Zhang, H., Zhang, K., Cao, H., Guo, Y., Yang, Z., 2020a. J. Control. Release 322, $187-199$.

Mao, K., Zhang, H., Wang, Z., Cao, H., Zhang, K., Li, X., Yang, Z., 2020b. Biosens. Bioelectron. 148, 111785.

Martin, A.J.P., Synge, R.L.M., 1941. Biochem. J. 35, 1358-1368.

Martinez, A.W., Phillips, S.T., Butte, M.J., Whitesides, G.M., 2007. Angew. Chemie - Int. Ed. 46, 1318-1320.

McConnell, E.M., Cozma, I., Morrison, D., Li, Y., 2020. Anal. Chem. 92, 327-344.

Ming, T., Wang, Y., Luo, J., Liu, J., Sun, S., Xing, Y., Xiao, G., Jin, H., Cai, X., 2019. ACS Sensors 4, 3186-3194.

Moghimi, N., Mohapatra, M., Leung, K.T., 2015. Anal. Chem. 87, 5546-5552.

Mohammadpour, Z., Majidzadeh-A, K., 2020. ACS Biomater. Sci. Eng. 6, 1852-1873.

Moskovits, Martin, 1985. Surface-enhanced spectroscopy. Rev. Mod. Phys. 57, 783-826.

Naderi, M., Hosseini, M., Ganjali, M.R., 2018. Spectrochim Acta A Mol Biomol Spectrosc 195, 75-83.

Noviana, E., McCord, C.P., Clark, K.M., Jang, I., Henry, C.S., 2020. Lab Chip 20, 9-34.

Pooja, D., Saini, S., Thakur, A., Kumar, B., Tyagi, S., Nayak, M.K., 2017. J. Hazard. Mater. 328, 117-126.

Putzbach, William, Ronkainen, Niina, J., 2013. Sensors, Vol. 13, Pages 4811-4840.

Quesada-González, D., Merkoçi, A., 2015. Biosens. \&amp; Bioelectron. 73, 47-63.

Ratajczak, K., Stobiecka, M., 2020. Carbohydr. Polym. 229, 115463.

Reboud, J., Xu, G., Garrett, A., Adriko, M., Yang, Z., Tukahebwa, E.M., Rowell, C., Cooper, J.M., 2019. Proc. Natl. Acad. Sci. 116, 4834-4842.

Ruscito, A., DeRosa, M.C., 2016. Front. Chem. 4, 1-14.

Saei, A.A., Dolatabadi, J.E.N., Najafi-Marandi, P., Abhari, A., de la Guardia, M., 2013. TrAC Trends Anal. Chem. 42, 216227.

Saraf, N., Bosak, A., Willenberg, A., Das, S., Willenberg, B.J., Seal, S., 2017. RSC Adv. 7, 49133-49143.

Shajaripour Jaberi, S.Y., Ghaffarinejad, A., Omidinia, E., 2019. Anal. Chim. Acta 1078, 42-52.

Sharma, B., Frontiera, R.R., Henry, A.I., Ringe, E., Duyne, R.P. Van, 2012. Mater. Today 15, 16-25.

Shi, H., Ge, S., Wang, Y., Gao, C., Yu, J., 2019. ACS Appl. Mater. Interfaces 11, 41062-41068.

Su, M., Ge, L., Ge, S., Li, N., Yu, J., Yan, M., Huang, J., 2014. Anal. Chim. Acta 847, 1-9.

Su, M., Ge, L., Kong, Q., Zheng, X., Ge, S., Li, N., Yu, J., Yan, M., 2015. Biosens. Bioelectron. 63, 232-239.

Vaishanav, S.K., Korram, J., Pradhan, P., Chandraker, K., Nagwanshi, R., Ghosh, K.K., Satnami, M.L., 2017. J. Fluoresc. 


\section{7, 781-789.}

Vashist, S.K., Luong, J.H.T., 2016. Biotechnol. Adv. 34, 137-138.

Wang, G., Wang, Y., Chen, L., Choo, J., 2010. Biosens. Bioelectron. 25, 1859-1868.

Wang, H., Zhou, C., Sun, X., Jian, Y., Kong, Q., Cui, K., Ge, S., Yu, J., 2018. Biosens. Bioelectron. 117, 651-658.

Wang, L., Zhu, F., Zhu, Y., Xie, S., Chen, M., Xiong, Y., Liu, Q., Yang, H., Chen, X., 2019. ACS Sensors 4, 3283-3290.

Wang, Y., Luo, J., Liu, J., Sun, S., Xiong, Y., Ma, Y., Yan, S., Yang, Y., Yin, H., Cai, X., 2019. Biosens. Bioelectron. 136, 8490.

Wei, B., Mao, K., Liu, N., Zhang, M., Yang, Z., 2018. Biosens. Bioelectron. 121, 41-46.

Wei, X., Tian, T., Jia, S., Zhu, Z., Ma, Y., Sun, J., Lin, Z., Yang, C.J., 2016. Anal. Chem. 88, 2345-2352.

Weng, X., Neethirajan, S., 2018. J. Food Saf. 38, e12412.

Wrzesinski, J., Jóźwiakowski, S.K., 2008. FEBS J. 275, 1651-1662.

Wu, L., Ma, C., Ge, L., Kong, Q., Yan, M., Ge, S., Yu, J., 2015. Biosens. Bioelectron. 63, 450-457.

Wu, L., Zhang, Y., Wang, Y., Ge, S., Liu, H., Yan, M., Yu, J., 2016. Microchim. Acta 183, 1873-1880.

Wu, Y.X., Kwon, Y.J., 2016. Methods 106, 21-28.

Xiao, K., Liu, J., Chen, H., Zhang, S., Kong, J., 2017. Biosens. Bioelectron. 91, 76-81.

Xue, J., Zhang, L., Gao, C., Zhu, P., Yu, J., 2019. Biosens. Bioelectron. 133, 1-7.

Yakoh, A., Chaiyo, S., Siangproh, W., Chailapakul, O., 2019. ACS Sensors 4, 1211-1221.

Yan, J., Yan, M., Ge, L., Yu, J., Ge, S., Huang, J., 2013. Chem. Commun. 49, 1383-1385.

Yang, B., Chen, B., He, M., Hu, B., 2017. Anal. Chem. 89, 1879-1886.

Yang, Y., Noviana, E., Nguyen, M.P., Geiss, B.J., Dandy, D.S., Henry, C.S., 2017. Anal. Chem. 89, 71-91.

Yao, Y., Jiang, C., Ping, J., 2019. Biosens. Bioelectron. 123, 178-184.

Yen, Y.-K., Chao, C.-H., Yeh, Y.-S., 2020. Sensors 20.

Yetisen, A.K., Akram, M.S., Lowe, C.R., 2013. Lab Chip 13, 2210-2251.

Zhang, L., Yang, Y., Tan, J., Yuan, Q., 2020. Mater. Chem. Front. 4, 1315-1327.

Zhang, X.-X., Liu, J.-J., Cai, Y., Zhao, S., Wu, Z.-Y., 2019. Analyst 144, 498-503.

Zhang, X., Bao, N., Luo, X., Ding, S.-N., 2018. Biosens. \&amp; Bioelectron. 114, 44-51.

Zhang, Z., Shikha, S., Liu, J., Zhang, J., Mei, Q., Zhang, Y., 2019. Anal. Chem. 91, 548-568.

Zhao, Y., Chen, F., Li, Q., Wang, L., Fan, C., 2015. Chem. Rev. 115, 12491-12545. 